\title{
EL ROMANCE DE LA REINA ELENA EN EL SIGLO XVI
}

\author{
JuAN CARLOS Bayo \\ ITEM-Universidad Complutense de Madrid \\ juanbayo@ucm.es
}

\section{INTRODUCCIÓN}

$\mathrm{E}$

1 texto del romance que comienza «Reina Elena, reina Elena» ha sido transmitido por cinco pliegos sueltos del siglo XVI; además, existen algunas breves pero preciosas referencias a él durante esa centuria. Hasta ahora no se ha elaborado una edición de tipo crítico que tenga en cuenta todos esos testimonios. Se trata, no obstante, de un trabajo necesario, pues se han llegado a glorificar como variantes de autor lo que no son sino meros descuidos de impresor. Cualquier comparación entre varios pliegos sueltos que contienen un mismo romance hace evidente que quienes trabajaban o colaboraban en los talleres se sentían libres de intervenir en el texto que preparaban si advertían en su modelo algo que les parecía un error, al mismo tiempo que introducían otros por distracción. Así se pone en marcha un proceso de modificación que, cuando incluye cambios conscientes e intencionales, puede generar variantes adiáforas y en los casos más extremos producir una versión distinta del poema original. Aun así, conviene recordar que en muchos casos las alteraciones se quedan en la fase de meros defectos y que, como sucede con cualquier texto transmitido por escrito, un romance conservado por pliegos y cancioneros del siglo XVI es susceptible de análisis ecdótico y no existe ninguna razón para no subsanar tales fallos mediante las herramientas de la crítica textual.

La primera edición moderna del romance de la reina Elena fue elaborada por Wolf y Hofmann en su Primavera y flor de romances a partir de dos pliegos sueltos conservados en Praga (1856: 3-7 [n. $\left.\left.{ }^{\circ} 109\right]\right)$. Menéndez Pelayo se limitó a retomarla junto al resto de la colección en su Antología de poetas líricos castellanos, sin apenas más retoque que su discutible decisión de disponer los versos en dos

Edad de Oro, XXXVII (2018), pp. 9-44, ISSN: 0212-0429 - ISSNe: 2605-3314

DOI http://dx.doi.org/10.15366/edadoro2018.37.001 
octosílabos por línea, si bien realizó valiosas observaciones sobre esta pieza al tratar de los romances de la Antigüedad grecolatina (1899: VIII, 221-223 [n. $\left.{ }^{\circ} 109\right]$; 1903: 480-484). Una nueva edición de tipo crítico, a partir de los dos pliegos de Praga ya mencionados y otro conservado en Madrid, fue elaborada por Diego Catalán en un estudio que no solo abordaba la cuestión del romance de la reina Elena en el siglo XVI, sino también su pervivencia en la tradición oral moderna (1970: 101-117). No obstante, la mayoría de los editores posteriores que lo han incluido en sus antologías se han limitado a retomar el texto de Menéndez Pelayo, aunque también ha habido una tendencia importante a remontarse directamente a uno solo de los dos pliegos de Praga, o bien el más antiguo (Débax 1982: 308-312 [n. ${ }^{\circ} 55$ ]; Díaz-Mas 1994: 386-390 [n. ${ }^{\circ}$ 99]), o bien el más completo (Di Stefano 1993: 237-239 [n. ${ }^{\circ}$ 60]; 2010: 201-204 [n. ${ }^{\circ}$ 64]). A continuación, me centraré en los testimonios directos o indirectos del siglo XvI, aunque las referencias a las raíces medievales y a las ramificaciones de la tradición sefardí resultarán inevitables.

\section{LOS TESTIMONIOS}

Cualquier análisis serio de un romance debe comenzar por considerar todos los testimonios conservados. Según se ha avanzado, se conservan cinco pliegos sueltos del siglo xvi que contienen el de la reina Elena. Existen, además, algunas referencias a él durante este periodo que tampoco se deben ignorar.

\subsection{LA TRADICIÓN DIRECTA: TESTIMONIOS QUE TRANSCRIBEN EL TEXTO}

Se trata de los ya mencionados cinco pliegos sueltos, los cuales, como suele suceder, no llevan marca de impresor, con una excepción, y tampoco indican ni el lugar ni el año de publicación. Sus características, sin embargo, hacen pensar que fueron producidos entre 1510 y 1565 aproximadamente, dos de ellos en Barcelona y tres en Burgos:

A I Romanze [con z invertida] dela reyna Clena [sic] con la glosa del | Romançe de Eneas. | [Enmarcado por una orla formada por cuatro piezas con motivos vegetales: una en el margen superior, dos en el derecho y una más ancha en el inferior. Esta incluye una marca tipográfica del impresor Carles Amorós, dos putti sosteniendo un escudo; en su interior se halla una mano empuñando un tallo con cinco ramas de olivo. Grabado formado por dos tacos xilográficos, el de la izquierda ocupa dos tercios y el de la derecha un tercio de la composición: $1 .^{\circ}$ ) Un caballero con armadura en el centro, con las murallas de una ciudad arriba al fondo, arrodillado ante una reina seguida de dos damas a la izquierda y cuatro árboles a la derecha; $2^{\circ}$ ) Una nao con la popa a la izquierda y la proa a la derecha. A continuación el texto a dos columnas]. 
1) - Reyna helena reyna helena $\mid$ dios prospere tu alto estado

2) ๆ Ay troyano quiē supiera $\mid$ qndo $[$ sic $]$ tu en mi puerto ètra $=\mid$ (ste

2 hojas; 4. ; letra gótica.

Barcelona, Biblioteca de Catalunya, 3-VI-8/20.

Asignación tipobibliográfica: Barcelona, Carles Amorós, ca. 1510?

Repertorios: Rodríguez-Moñino (1997), n. ${ }^{\circ} 1011$ bis; Lamarca (2015), n. ${ }^{\circ} 75$.

Facsímil: Pliegos poéticos del siglo XVI de la Biblioteca de Cataluña, n. ${ }^{\circ} 38$.

B If Romance nueuo por muy gentil | estilo: con vna glosa nueua al romance $\overline{\mathrm{q}}$ dize En castillla [sic] | esta vn castillo que se llama rocha frida. Y el romāce de a [sic] reyna Elena. Y vnas coplas y villancicos. | [Grabado con una escena enmarcado en doble filete: en el centro un caballero con una dama en la grupa de su montura, dirigiéndose a un castillo a la izquierda y seguido por un escudero con dos cabalgaduras a la derecha. A continuación el texto a dos columnas].

1) I Por un bosq̄ tenebroso $\mid$ caminando triste vn dia

2) ๆ Porq̄ en tal caso y tenor $\mid$ se publique nueua historia

3) ๆ Porā me beso perico | porā me beso el traydor

4) Reyna elena reyna elena $\mid$ dios prospere tu alto estado

5) I Bendito sea aquel dia $\mid$ que nacio mi pensamiento

6) ๆ Pues mi vida $\tau$ e vāa vida | vna vida son las dos

4 hojas; 4. ; letra gótica.

Praga, Národní knihovna České republiky, 9.H.231/71.

Asignación tipobibliográfica: Burgos, Alonso de Melgar, ca. 1520?

Repertorios: Rodríguez-Moñino (1997), n. ${ }^{\circ}$ 1048; Fernández-Valladares (2005), n. ${ }^{\circ} 116$.

Facsímil: Pliegos poéticos españoles en la Universidad de Praga, n. $^{\circ} 71$.

C I Glosa del Romançe de don Tristan y la $\mid$ glosa del romāçe que dize. Reyna Elena | y vnas coplas de Bēditos sean mis ojos $\mid \tau$ la glosa del romançe de Eneas. [Enmarcado por una orla completa formada por ocho piezas. Grabado formado por cuatro tacos xilográficos de aproximadamente el mismo tamaño: $\left.1 .^{\circ}\right)$ Árbol con tres pájaros. $2^{\circ}$ ) Mujer desnuda, con la mano izquierda cogiendo un paño que le cuelga del hombro derecho y con la mano derecha alzando un objeto similar a una redoma con una pócima. $3 .^{\circ}$ ) Galán. $4 .^{\circ}$ ) Ciudad. A continuación el texto a dos columnas].

1) đAl tiēpo que se alegraua | el campo cō nueuas flores

2) ๆ Reyna Elena reyna Elena $\mid$ dios prospere tu alto estado

3) I Bendito sea aquel dia $\mid$ que naçio mi pensamiento

4) ๆ Pues mi vida y vīa vida | vna vida son las dos

5) ๆ Ay troyano quien supiera $\mid$ quādo tu è mi puerto ètraste 
4 hojas; 4. ; letra gótica.

Paradero desconocido, quizá en Barcelona.

Asignación tipobibliográfica: Barcelona, Carles Amorós, ca. 1540?

Repertorios: Rodríguez-Moñino (1997), n. ${ }^{\circ} 883.5$; Lamarca (2015), n. ${ }^{\circ} 266$.

Facsímil: Cátedra (1983), n. ${ }^{\circ} 4$.

D Tlosa del romance de dō Tristan. | Y el romance que dizen dela reyna Elena. Y vn villācico $\mid$ de passes me por Dios barquero. Y otro villancico đ $\mid$ romerico tu que vienes. Y otro que dize. No me $\mid$ demandes carillo, que a ti no te me daran. [Grabado enmarcado en doble filete y flanqueado a derecha e izquierda por sendas barras de adornos tipográficos; es una escena que representa conversaciones simultáneas entre dos grupos de personajes por separado en un palacio: a la izquierda, un rey con tres hombres; a la derecha, otros tres hombres. A continuación el texto a dos columnas].

1) AL tiempo $\bar{q}$ se alegraua $\mid$ el cāpo con nueuas flores

2) $\mid$ REyna elena reyna elena $\mid$ dios prospere tu estado

3) ๆ Passesme por dios barq̄ro | de aquessa parte del rio

4) ๆ ROmerico tu que vienes $\mid$ donde mi señora esta

5) NO me demādes carillo | pues que no te medarā

4 hojas; 4. ; letra gótica.

Praga, Národní knihovna České republiky, 9.H.231/18.

Asignación tipobibliográfica: Burgos, Felipe de Junta, ca. 1564 ?

Repertorios: Rodríguez-Moñino (1997), n. ${ }^{\circ} 883$; Fernández-Valladares (2005), n. ${ }^{\circ} 529$.

Facsímil: Pliegos poéticos españoles en la Universidad de Praga, n. ${ }^{\circ} 18$.

E - Glosa del romance de don Tristā. | Y el romance que dizen dela reyna Elena. Y vn villācico | de passes me por Dios barquero. Y otro villancico de $\mid$ romerico tu que vienes. Y otro que dize. No me $\mid$ demandes carillo, que a ti no te me daran. [Grabado enmarcado en doble filete y flanqueado a derecha e izquierda por sendas barras de adornos tipográficos; es una escena que representa en un palacio a un caballero con ropa de viaje arrodillado ante una dama, entre dos doncellas de esta a la izquierda y otros dos personajes a la derecha. A continuación el texto a dos columnas].

1) AL tiempo $\bar{q}$ se alegraua $\mid$ el cāpo con nueuas flo= $=\mid$ (res

2) T Reyna elena reyna elena $\mid$ Dios prospere tu estado

3) ๆ Passes me por Dios varq̄ro $\mid$ de aquessa parte del rio

4) ๆ ROmerico tu que vienes $\mid$ donde mi señora esta

5) ๆ NO me demādes carillo $\mid$ pues $\bar{q}$ no te me daran

4 hojas; 4. ; letra gótica.

Madrid, Biblioteca Nacional de España, R/9425. 
Asignación tipobibliográfica: Burgos, Felipe de Junta, ca. 1565 ?

Repertorios: Rodríguez-Moñino (1997), n. ${ }^{\circ} 882$; Fernández-Valladares (2005), n. ${ }^{\circ} 550$.

Facsímil: Pliegos poéticos góticos de la Biblioteca Nacional, n. ${ }^{\circ} 68$.

He aceptado en general las dataciones por asignación tipobibliográfica recogidas en Lamarca (2015) y Fernández Valladares (2005). Aunque a veces podrían plantearse dudas, considero que la cronología relativa resulta correcta. Los dos testimonios barceloneses proceden del taller de Carles Amorós, cuya actividad como impresor de 1507 a 1548 está bien documentada. El primero es un medio pliego, a diferencia del otro y todos los demás, los cuales son pliegos enteros. La pieza de la orla inferior con los dos putti aparece ya en una impresión de la obra de Francesc Eiximenis De la temor de Déu, con colofón de 1509, y se sigue utilizando en las Cobles en lahor de la Christianíssima Pau de 1526 (Fernández Vega 2003: 80), pero en estos dos casos el escudo se halla en blanco; hay que advertir que la marca con la mano empuñando el tallo de olivo comienza a documentarse hacia 1520. Los grabados fueron utilizados también en su edición ampliada de las Històries e conquestas de Pere Tomic en 1534, en concreto el del caballero y la reina en los ff. $16 \mathrm{v}$ y $48 \mathrm{r}$ y el del barco en el f. $54 \mathrm{v}$.

Lamentablemente, el otro testimonio, sin marca de impresor, atribuido a Carles Amorós resulta solo accesible por la edición facsímil de Cátedra (1983), pues se halla en manos de un coleccionista privado, quizá en Barcelona (Di Stefano 1988: 272) ${ }^{1}$. Su editor desarrolla la hipótesis de que podría tratarse de una iniciativa de Pere Montpezat en colaboración con Carles Amorós. Hay un par de puntos débiles: por una parte, no hay pruebas de que Pere Montpezat llevara a cabo impresión de romances; por otra parte, Carles Amorós utilizó a lo largo de su carrera muy variadas letrerías, a menudo obtenidas de otros impresores. Cátedra advierte que en este pliego suelto parece haberse empleado una procedente del taller de Joan Rosembach y cita un documento notarial del 15 de junio de 1529 por el que este se comprometía a ceder al cabo de tres años una prensa y cuatro letrerías a Pere Montpezat, que había de casarse con una criada del impresor alemán (Madurell y Rubió 1955: 699-703 [n. $\left.{ }^{\circ} 400\right]$ ]). Sin embargo, Rosembach murió en los primeros días de noviembre de 1530 , las condiciones del contrato no se cumplieron y el taller del difunto, con los materiales correspondientes, pasó a propiedad de Carles Amorós según recoge un documento del 7 de junio de 1531 (Madurell y Rubió 1955: 719-720 [n. $\left.\left.{ }^{\circ} 410 \mathrm{bis}\right)\right]$. Parece, pues, más simple asignar el pliego a este impresor.

$1 \quad$ La entrada en la base de datos Iberian Books dirigida por Wilkinson lo clasifica como probable fantasma bibliográfico, lo cual acaso sea una prevención excesiva $<$ https://iberian.ucd.ie/view/ iberian:18827>. 
Si los testimonios barceloneses debieron de salir todos del local de Carles Amorós en la calle de la Portaferrissa, los burgaleses también podrían proceder de un solo lugar, el establecimiento en el Azogue fundado por Fadrique de Basilea. Esta imprenta fue heredada por su hija Isabel y su yerno y antiguo oficial Alonso de Melgar, quien estuvo al frente del negocio desde 1518 hasta su muerte en 1525; la viuda se casaría poco después con Juan de Junta y el hijo de ambos, Felipe de Junta, se haría cargo personalmente de este taller desde 1560 hasta su muerte en 1596. La asignación del testimonio burgalés más temprano a Alonso de Melgar hacia 1520 fue ya realizada por Norton (1978: 121-122 [n. $\left.\left.{ }^{\circ} 340\right]\right)$ y es apoyada por Fernández Valladares (2006: 463), quien precisa que no puede ser anterior a noviembre de 1519 y además indica que el grabado fue utilizado hasta 1558 (2012: 110-111). Los otros dos pliegos burgaleses, ambos asignados a Felipe de Junta, ofrecen el mismo contenido y son muy similares y próximos en el tiempo. Fernández Valladares sitúa el conservado en Praga hacia 1564 (2006: 471) y el custodiado en Madrid entre 1560 y 1565 (2006: 469). En cuanto a sus grabados, indica que el del primero fue ya utilizado en un pliego al parecer impreso entre 1515 y 1519 por Fadrique de Basilea o Alonso de Melgar, mientras que el del segundo lo documenta por primera vez hacia 1563 (2012: 113). Como se verá más adelante, el texto del pliego conservado en Madrid es algo inferior al de Praga e incluso se puede llegar a plantear la hipótesis de que desciende de él, por lo que he preferido datarlo simplemente hacia 1565 .

\subsection{LA TRADICIÓN INDIRECTA: TESTIMONIOS QUE SOLO MENCIONAN O CITAN EL ROMANCE}

Existen tres testimonios que, a pesar de no contener el texto del romance de la reina Elena o citarlo muy pasajeramente, deben ser considerados. Se trata del llamado Libro de cincuenta romances, los catálogos de la Biblioteca Colombina - en particular el Abecedarium $B$ - y un pliego suelto con una ensalada de romances viejos donde se citan los dos primeros versos.

a Libro en el qual $\mid$ se contienen cincuenta romançes cō $\mid$ sus vilancicos y desechas. Entre los | quales ay muchos dellos nueuamen | te añadidos: que nunca en estas tier $=\mid$ ras se han oydo. [Enmarcado con orla completa formada por ocho piezas con motivos vegetales. Debajo del título grabado formado por dos tacos xilográficos: un tañedor de guitarra y una dama].

[A la vuelta se halla descripción del contenido]: AQui comiençan cinquenta romā= | çes en los quales han $[$ sic $]$ añadidos los siguentes $[$ sic $]$ romā $\mid$ çes. El romançe de Calisto $\tau$ Melibea. Otro $\bar{q} \mid$ comiença En las salas de Paris. Otro đ Gua $\mid$ rinos Otro de gayferos Otro al conde de Oliua. Otro đl $\mid$ conde Claros. Otros tanbien de amores. Otro đ la Reyna | helena. Otros đ Paris y las tres deesses. Y muchos otros ro $\mid$ mances. 
4(+2) hojas (incompleto); 4. ${ }^{\text {o }}$ letra gótica.

Paradero desconocido.

Asignación tipobibliográfica: Barcelona, Carles Amorós, ca. 1525?

Repertorios: Rodríguez-Moñino (1997), n. ${ }^{\circ}$ 936(+1063); Lamarca (2015), n. ${ }^{\circ} 215$.

Facsímil: Pliegos poéticos de la colección del marqués de Morbecq, $\mathrm{n}^{\circ}{ }^{\mathrm{o}}$ 4(+5).

$b \quad$ [Abecedarium B, cols. 538, 542, 1138 y 1153, n. $\left.^{\circ} 12308\right]$

$538 /$ = Elena en romançe -12308

$542 /=$ Emperatrices y reynas $\overline{\mathrm{q}}$ huys de la legria -12308

$1138 /$ = reginae coplas -12308

1533/ Reyna elena reyna elena dios prospere tu estado - 12308

Pliego suelto perdido.

Repertorios: Rodríguez-Moñino (1997), n. ${ }^{\circ} 857$.

c If Aqui comiença vn romance de vn | desafio entre don Urgel y Bernardo del Carpio. | Mas una ensalada de muchos roman | ces viejos y cantarcillos. [Grabado enmarcado por cuatro barras con la escena de dos caballeros lidiando en una playa, con un castillo a la izquierda y el mar a la derecha. A continuación el texto a dos columnas. En la segunda de la página final se halla la penúltima estanza de la «Ensalada de romances viejos» con los siguientes versos]:

Reyna Elena Reyna Elena

Dios prospere vuestro estado

4 hojas; 4. ; letra gótica.

Praga, Národní knihovna České republiky, 9.H.231/1.

Asignación tipobibliográfica: Burgos, Felipe de Junta, ca. 1570?

Repertorios: Rodríguez-Moñino (1997), n. ${ }^{\circ}$ 707; Fernández-Valladares (2005), n. ${ }^{\circ} 587$.

Facsímil: Pliegos poéticos españoles en la Universidad de Praga, n. $^{\circ} 1$.

La asignación tipobibliográfica del Libro de cincuenta romances fue realizada por Rodríguez Moñino en su introducción a la edición facsímil. En particular, llamó la atención sobre una letra de gran tamaño utilizada en la portada y otra menor de encabezamiento utilizadas en el taller de Joan Luschner y después en el de Carles Amorós. Las del texto aparecen en una fundición utilizada por este en un libro de 1518 , pero con la adición de dos nuevas formas para la $M$ que llevan a suponer que el Libro de cincuenta romances es siete u ocho años posterior.

Los repertorios de la Biblioteca Colombina son de capital importancia y la inclusión de un impreso en ellos significa que fue adquirido, y lógicamente producido, antes de la muerte de Hernando Colón, acaecida en Sevilla el 12 de julio de 
1539. En el Abecedarium $B$ figuran tanto el pliego atribuido más arriba a Alonso de Melgar (n. ${ }^{\circ}$ 12361) como el Libro de cincuenta romances (n. $\left.{ }^{\circ} 14870\right)^{2}$. Es del mayor interés la referencia, también en el Abecedarium $B$, a un pliego hoy perdido (n. $\left.{ }^{\circ} 12308\right)$ y según la numeración más temprano que el atribuido a Alonso de Melgar: en él aparecían el romance de Elena y las coplas de la reina de Nápoles, sin ninguna indicación de que contuviera más textos; debió de tratarse, pues, de un medio pliego, probablemente similar al conservado de Carles Amorós.

Estos dos medios pliegos muestran claramente que los impresores intentaban incluir en ellos poesías con alguna vinculación. El romance de Elena y Paris es seguido por una composición sobre Dido y Eneas en el de Carles Amorós - destinado, pues, a la materia troyana en sentido estricto-, mientras que era complementado por las coplas de la reina de Nápoles en el hoy perdido - dedicado así a soberanas desgraciadas-. La actitud de los impresores está en consonancia con la de los poetas. En realidad, al autor del romance que nos ocupa le interesa más el rapto de Elena y el castigo de Paris que la guerra de Troya en sí, que queda relegada a un segundo plano. Por regla general, los romances más antiguos de materia troyana se centran en reinas y princesas envueltas en la guerra en el bando iliense, finalmente perdedor: aparte de Elena, se hallan Pentesilea y Políxena - la reina de las amazonas en «Por los montes de Carcaso», la joven princesa troyana en « $i \mathrm{Oh}$ cruel hijo de Archiles!» y «Triste estava e muy penosa» (ed. Menéndez Pelayo 1899: IX, 214-216 [Apéndice a la "Primavera» n. $\left.\left.{ }^{\text {s }} 31-33\right]\right)$ -

La situación se complica en el caso de los pliegos enteros por su mayor extensión, pero aun así hay que notar el predominio de la temática erótica desde una perspectiva caballeresca, muy en la órbita del llamado amor cortés. El testimonio más reciente de Carles Amorós vuelve a presentar las dos obras de su medio pliego anterior precedidas por otra nueva, la glosa del romance de Tristán atribuida a Alonso de Salaya en otros pliegos, la cual también encabeza los dos testimonios asignados a Felipe de Junta. Estamos, pues, ante tres casos de parejas de amantes - Paris y Elena, Dido y Eneas, Tristán e Iseo- con mucho en común: se trata de relaciones entre una reina (o princesa destinada a serlo) y un noble con menor estatus que tendrán consecuencias funestas. Esta fijación en el aspecto erótico de la leyenda troyana tiene raíces medievales. Ya el Roman de Troie de Benoît de Sainte-Maure, compuesto en la década de 1160, y la Historia destructionis

2 Es acaso posible que lo que Askins e Infantes interpretaron como una referencia en el Supplementum, f. $16 \mathrm{v}$, a uno de los pliegos impresos por Felipe de Junta por los años de 1560 remitiera en realidad al asignado más arriba a Carles Amorós hacia 1540 si se adelanta ligeramente la fecha de este; no obstante, debo confesar que ignoro los motivos por los que añadieron tal información a Rodríguez-Moñino (1997: 691-692 [n. $\left.{ }^{\circ} 882\right]$ ), pues lo único que se lee en el facsímil que puede guardar alguna relación es «Glosa», sin más indicación. 
Troiae de Guido delle Colonne (Guido de Columnis en latín), acabada en 1287, se articulaban en gran medida en torno a cuatro relaciones con triste final: Jasón y Medea, Paris y Elena, Troilos y Briseida, Aquiles y Políxena. La influencia de ambas obras en las literaturas hispánicas fue considerable, como se ilustrará más adelante. Aquí tan solo cabe añadir que en la Edad Media se prolongaba la historia de Troya no solo con el establecimiento de Eneas en Roma, sino además con el de su descendiente Bruto en Bretaña. Así se encuentra en Guido y en obras que lo utilizaron como fuente, entre ellas la Crónica troyana cuya primera impresión en 1490 fue seguida de más de una docena de ediciones hasta 1587. Las historias de Paris y Elena y de Tristán e Iseo, pues, guardaban mayor relación para el público de la época que para el actual.

Finalmente, el último testimonio indirecto de relevancia es un pliego que termina con una ensalada anónima de romances viejos, a veces denominada «ensalada de Praga». Aunque solo transmita dos versos del protagonizado por Paris y Elena, proporciona valiosas indicaciones sobre su difusión y cómo se cantaba en el siglo XVI.

\section{LA RELACIÓN ENTRE LOS TESTIMONIOS}

En primer lugar, hay indicios de que los cinco pliegos que han transmitido el texto del romance por extenso provienen de un solo ascendiente ya defectuoso, presumiblemente un pliego. El primer ejemplo significativo aparece en el mismo inicio y muestra la relevancia de los testimonios indirectos ${ }^{3}$ :

1)

2 Dios prospere vuestro estado $c$

dios prospere tu estado $\quad b D E$

dios prospere tu alto estado $A B C$

La lección de la ensalada, «vuestro», es la más consistente con el texto del romance, incluso a pesar de acabar aquí su cita, pues Paris se dirige a Elena utilizando vos en el resto del poema. Probablemente, un ascendiente común de los cinco pliegos que han transmitido el texto por extenso leía por error «tu», una lección hipométrica si se hace sinalefa; esto llevó al remiendo «tu alto», que a su vez suscita un posible problema de sentido, esto es, si una reina puede ascender de estado. Ambas lecciones, pues, plantean dificultades y de ahí las vacilaciones en la transmisión.

3 Dadas las coincidencias en lugares de impresión y de conservación, designo los testimonios alfabéticamente. Cuando aparecen microvariantes, cito en general solo la lección tal como aparece en la mayoría de los testimonios. 
2)

31 echo la compuerta Paris $A B C D E$

El resto del texto indica que el nombre de este príncipe troyano tenía acentuación antietimológica oxítona, París, lo cual hace que este verso resulte hipermétrico. Ello hace pensar que la lección original debió de ser *echó París la compuerta y hubo un cambio de orden de palabras en un ascendiente común. Cabe añadir que la acentuación oxítona se ve apoyada por la tradición oral de este romance, como ya advirtió Menéndez Pelayo (1903: 482 n. 3).

3)

$\begin{array}{ll}\text { alçen ancoras tiendan velas } & B C D \\ \text { alcen ancoras tiendas velas } & A \\ \text { alcen ancoras y velas } & E\end{array}$

Aquí la lección de la mayoría es la del ascendiente común, pero resulta hipermétrica y el editor del testimonio más reciente introdujo un remiendo. Este muestra en otros lugares preocupación por la métrica; en algunos casos, sus retoques son obvios y pueden considerarse acertados, pero aquí hay problemas para aceptar su intervención. El tipo de estructura bimembre que aparece en la lección de la mayoría no solo es común en el estilo del romancero, sino que aparece en este pasaje en versiones de la tradición sefardí. El texto de Yacob Abraham Yoná en su Gu'erta de romansos 'importantes (Salónica, antes de 1905) lee «Armó velas 'i 'eğó ganğo» (v. 12, transcripción de Armistead y Silverman 1971: 145 [n. $\left.{ }^{\circ} 11 \mathrm{a}\right]$ ), mientras que una versión de Tetuán recogida más recientemente contiene «Alzan velas y echan remos» (v. 21, repetido en v. 22, ed. Larrea 1952: 134-135 [n. $\left.{ }^{\circ} 26\right]$ ). Es probable, pues, que haya un error debido a que áncoras haya sustituido a un equivalente bisílabo como anclas o ganchos (en la época, áncora, forma conservada en otras lenguas románicas peninsulares, no tenía un matiz tan arcaico y culto como en la actualidad).

Los dos últimos ejemplos nos han llevado a la cuestión de las versiones de este romance recogidas en tiempos recientes. Es cierto que no se pueden mezclar indiscriminadamente los testimonios impresos del siglo XVI con tales textos, pero tampoco es lícito, ni prudente, ignorar la tradición oral. En la inmensa mayoría de las versiones tomadas de esta aparecen en el lugar que seguiría al v. 12 de los pliegos del siglo XVI unas palabras de Paris explicando que en su nave lleva un árbol maravilloso con manzanas de amor, algo quizá más apto para estimular la curiosidad de la reina. Así habla en la versión ya citada de Yoná (Armistead y Silverman 1971: 145):

4) 7 De la nave ke yyo vengo, aví'a 'un riko mansano, ke 'eğava mansanas de amores 'invyerno 'i 'enverano. 
Se trata un motivo literario de carácter fantástico inspirado en el juicio de Paris, pero a la vez correspondiente a la mentalidad folklórica y susceptible de ser adoptado por ella. Su gran difusión en la tradición oral, pues aparece en versiones recogidas en Canarias, Marruecos y Turquía, induce a pensar que figuraba en la composición original tal como se debió de cantar a finales del siglo xv (Armistead y Silverman 1971: 149) y que los versos correspondientes fueron eliminados al componer el texto en un pliego ascendiente de los conservados.

Si se sigue con el análisis, hay una veintena de variantes que muestran con bastante claridad que los dos pliegos asignados a Felipe de Junta en la década de 1560 están estrechamente relacionados. Por motivos de espacio, selecciono solo un ejemplo (el resto se puede espigar en el aparato crítico que figura más adelante):

5) 105 Troylos $A B C$ : Troylo $D E$

Aquí los testimonios más tempranos mantienen la $-s$ grecolatina ( $<$ lat. TRoILus

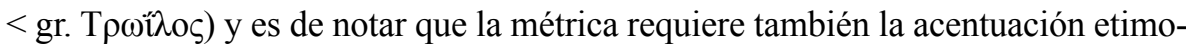
lógica. Este príncipe troyano es mencionado otra vez en el v. 119 y los pliegos asignados a Felipe de Junta vuelven a utilizar la forma $\sin -s$ final frente a los demás.

Que los dos testimonios impresos por Felipe de Junta hacia mediados de la década de 1660 estén fuertemente emparentados era hasta cierto punto de esperar. Lo que resulta algo más sorprendente es que una quincena de variantes muestran con bastante claridad que los textos impresos por Alonso de Melgar hacia 1520 y por Carles Amorós hacia 1540 se encuentran estrechamente relacionados entre sí, mucho más de lo que se halla el primero con los atribuidos a Felipe de Junta o el segundo con el previamente estampado por el mismo impresor. Este es un ejemplo:

6)

113 bien vengades vos Paris $A D E$

bien vengays vos Paris $B C$

Aquí la sustitución por la forma más evolucionada del verbo produce hipometría en los dos testimonios datados hacia 1520-1540.

En este punto hay que considerar una laguna que ha llegado a ser objeto de comentario en la bibliografía sobre el romancero, aunque teniendo en cuenta solo los pliegos sueltos burgaleses:

7)

93
Agamenon que esto vido
mando apercebir su real
pone en orden su gente
como auia de estar

$A D E$ 


\section{Agamenon questo vido $B C$ mando apercebir su gente como auian destar}

La última lección es claramente defectuosa y hace daño a la vista en las ediciones que siguen el texto del pliego asignado a Alonso de Melgar disponiendo dos octosílabos por línea. Se trata de un caso evidente de homoioteleuton o salto de igual a igual, es decir del «su» del v. 94 al «su» del siguiente, y como tal es mencionado por Di Stefano (2016: 120) sin entrar en explicaciones. En cambio, Garvin (2007: 104-105) propone que la lección más completa corresponde a una modificación introducida en el taller de Junta sobre el texto tal como es transmitido por el pliego asignado a Alonso de Melgar hacia 1520. Este tipo de explicación es altamente improbable incluso considerando únicamente los testimonios burgaleses, pues, aunque un corrector introduzca una enmienda, resulta muy remota la posibilidad de que lo haga reproduciendo las condiciones para un homoioteleuton. Naturalmente, la prueba definitiva de que la lección de los pliegos más recientes es la original es que esta aparece ya en el más antiguo, el estampado hacia 1510 por Carles Amorós ${ }^{4}$. Todo indica que en la imprenta de Felipe de Junta se siguió el texto de un pliego que en este pasaje era diferente y mejor que el atribuido al primer marido de su madre, Alonso de Melgar. En cualquier caso, la laguna es un evidente error de impresor y resulta inadmisible mantenerla en una edición que vaya más allá de la transcripción paleográfica de un solo testimonio.

Esto nos lleva a la relación que tiene el pliego más antiguo conservado, el impreso por Carles Amorós hacia 1510, con el resto. Hay un par de variantes que obligan a asumir que no fue el ascendiente de ninguno de los otros testimonios conservados. La más interesante es la siguiente:

8)

$\begin{array}{ll}\text { a esse buen rey castellano } & B C \\ \text { a esse buen rey Castellano } & D E \\ \text { a esse buen rey de françia } & A\end{array}$

Aquí el impresor del pliego más antiguo parece haber interpretado el «castellano» original confiriéndole sentido gentilicio, «de Castilla» (probablemente su modelo leía además «Castellano» con mayúscula como los testimonios más estrechamente emparentados) en vez de con la acepción «señor de un castillo» (habitualmente, aunque no aquí, solo como gobernador) y a raíz de ello haber

\footnotetext{
4 Incluso si hubiera que retrasar algo su fecha, la cronología seguiría siendo contundente en contra de una innovación, pues el impresor provenzal murió en 1549, una década antes de que Felipe de Junta heredara el taller burgalés.
} 
introducido un remiendo poco acertado (rompe con la asonancia, aparte de introducir un cambio de significado desafortunado para el lector actual).

Además, el pliego más antiguo de Carles Amorós se acerca a los atribuidos a Felipe de Junta de modo que hace posible explicar algunas variantes:

9) 14 Agamenon los regia $B C$

Agamenon los guia $A$

Agamenon los guiaua $D E$

La lección original debió de ser «regia», que en un descendiente fue modificada por error a «guia» según refleja el testimonio más antiguo de Carles Amorós. Tal variante resulta hipométrica y se ve enmendada en los testimonios atribuidos a Felipe de Junta a «guiaua», que en lo que respecta tanto al significado como a la métrica es tan válida como «regia».

El siguiente paso es perfilar la relación entre los dos grupos de testimonios ya establecidos. Por lo que hace a los pliegos atribuidos a Felipe de Junta, hay unos cinco ejemplos en los que el conservado en Praga coincide con los otros frente al de Madrid. Constituyen un indicio inequívoco de que este último, pese a introducir retoques para mejorar la métrica, es un testimonio inferior. Este es el ejemplo más claro:

10) 115 por Troya $A B C D$ : por la tierra $E$

La primera lección hace mejor sentido y se halla confirmada por los otros tres testimonios.

Ahora llega el momento de plantear si el pliego de Felipe de Junta conservado en Madrid desciende del otro del mismo impresor custodiado en Praga. Aunque quizá no sea del todo imposible, resulta improbable, pues hay tres casos en los que llega a coincidir con los testimonios de la primera mitad del siglo frente al otro. Uno de ellos es el siguiente:

11) 70 en ella estan $D:$ en ellas estan $A B C E$

Aquí la lección correcta es la primera, tanto desde el punto de vista métrico (hace posible una sinalefa necesaria para el octosílabo) como gramatical (el antecedente del pronombre es «villa», en singular). La conclusión es que el vínculo entre los dos testimonios asignados a Felipe de Junta no es directo, sino que se produce por medio de un ascendiente común. Es interesante notar que Di Stefano (1988: 275-276) se inclinaba por esta misma relación al considerar el texto del romance glosado de don Tristán transmitido por estos dos mismos pliegos. Todo indica, pues, que fueron compuestos en la imprenta de Felipe de Junta a 
partir de otro anterior de igual contenido, probablemente estampado en el mismo taller.

En cuanto a la relación entre los pliegos asignados a Alonso de Melgar hacia 1520 y a Carles Amorós hacia 1540, hay indicios de que el texto de este es inferior, aunque la evidencia sea menor. Este es un ejemplo:

12) 50 malamente os ha engañado $A D E$ malamente os an engañado $B$ malamente os han gañado $C$

El sujeto es «Paris» (v. 47) pero los dos testimonios en cuestión muestran un error, el paso del verbo al plural por atracción de «sus palabricas» (v. 49). El pliego atribuido a Alonso de Melgar reproduce la lección equivocada de su ascendiente, mientras que el posterior de Carles Amorós introduce un remiendo para restaurar la métrica, pero sigue adoleciendo de incorrección gramatical.

El nombre de un personaje también da pie a variantes en ambos testimonios:

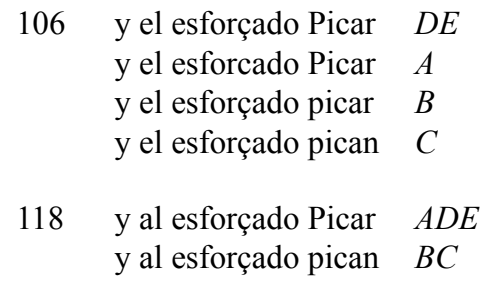

Cátedra argumenta que la lección correcta es «Pican, de acuerdo con la historia de Troya» (1983: 34), pero tal forma no se documenta en ninguno de los tratamientos medievales de la materia troyana ni en sus aledaños según he podido comprobar. Así pues, me parece claramente preferible la forma «Picar», seguramente invención del poeta, por ser lección superior.

La última cuestión es averiguar si el texto del pliego asignado a Alonso de Melgar es ascendiente directo del que ofrece el atribuido a Carles Amorós hacia 1540. De nuevo, no es una hipótesis del todo descartable, pero resulta un tanto improbable. Un aspecto que diferencia a estos dos testimonios de los demás es que son los únicos que presentan casos de $-e$ paragógica. Ahora bien, mientras que en el pliego burgalés hay solo uno, «sale» (v. 68), en el barcelonés hay cuatro, «derribare» (v. 66), «salle» (v. 68), «naturale» (v. 126) y «caualgare» (v. 138). Parece más natural suponer que la paragoge figuraba en el modelo y fue suprimida por los impresores que al contrario. Ello, sumado a que es improbable una relación directa o casi directa entre dos testimonios en un corpus con pérdidas masivas, hace más prudente pensar que el pliego asignado a Carles Amorós hacia 1540 no deriva del atribuido a Alonso de Melgar, sino de un ascendiente común a ambos. 
Este sería, pues, el stemma del romance de la reina Elena en los cinco pliegos conservados:

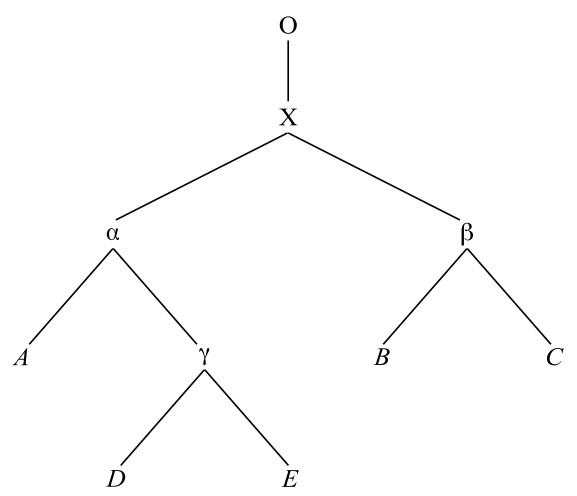

\section{Edición DEL ROMANCE DE LA REINA Elena}

A continuación presento una edición del romance de la reina Elena, seguida de un aparato de variantes, teniendo en cuenta todos los testimonios. He consultado directamente los pliegos conservados en la Biblioteca de Catalunya y la Biblioteca Nacional de España. En el caso de los de Praga, me he basado en la digitalización disponible en la página correspondiente de la red <http://www.manuscriptorium. com>. En cuanto al asignado a Carles Amorós hacia 1540, he utilizado el facsímil por ser la única fuente accesible ${ }^{5}$. Aunque he seleccionado variantes de los testimonios directos e indirectos, me he abstenido de introducir enmiendas ope ingenii; a causa de ello, han quedado dos versos hipermétricos. No he intentado reconstruir la - e paragógica, que probablemente figuraba en el original, pero que también pudo ser introducida en el subarquetipo $\beta$. Además de añadir acentos y puntuación y resolver las abreviaturas, se ha regularizado el uso de $i / j / y$ y $u / v$, pero se ha evitado modernizar otras consonantes, en particular las sibilantes (en el aparato de variantes se mantienen las grafías según aparecen en los pliegos, si bien se desarrollan las abreviaturas).

$5 \quad$ He consultado los facsímiles disponibles de los cinco pliegos, pero resulta preferible la inspección del original e incluso de reproducciones fotográficas a causa de los retoques y equivocaciones que a veces se introducen en tales ediciones. En el caso del pliego de la Biblioteca Nacional de España, se pueden advertir las siguientes falsas erratas y correcciones (doy primero la lectura del pliego y después la del facsímil): 57 vn: va; 85 guiaua: guiana; 118 esforçado: esforcado; 121 dnque: duque. 
-Reina Elena, reina Elena,

Dios prospere vuestro estado.

Si mandáis alguna cosa, veisme aquí a vuestro mandado.

5 -Bien vengades vos, París,

París el enamorado.

París, ¿dónde avéis camino?

¿Dónde tenéis vuestro trato?

-Por la mar ando, señora,

10 hecho un terrible cossario.

Traigo un navío muy rico, de plata y oro cargado;

llévolo a presentar

a esse buen rey castellano-.

15 Respondiérale la reina,

d'esta suerte le ha hablado:

- Tal navío como aquesse

razón era de mirallo-.

Respondiérale París

20 muy cortés y mesurado:

-El navío y yo, señora, somos a vuestro mandado.

- Gran plazer tengo, París, como venís bien criado.

25 - Vayádeslo a ver, señora; veréis cómo va cargado.

—Plázeme — dixo la reina-

por hazer vuestro mandado.-

Con trezientas de sus damas

30 a la mar se ha llegado.

Echó la compuerta París

hasta que ovieron entrado;

desque todas fueron dentro,

bien oiréis lo que ha mandado:

35 — ¡Alcen áncoras, tiendan velas!-

y a la reina se ha llevado.

Lunes era, cavalleros,

un día fuerte y aziago,

cuando entró por la sala

40 aquesse rey Menalao,

messando de las sus barvas,

fuertemente sospirando, sus ojos tornados fuentes, de la su boca hablando: 
45 - Reina Elena, reina Elena, ¿quién de mí os ha apartado? Aquesse traidor París, el señor de los troyanos, con las sus palabras falsas

50 malamente os ha engañado-. ¡Tan bien se lo consolava don Agamenón su hermano! -No lloredes vos, el rey, no hagades tan gran llanto,

55 qu'el llorar y solloçar a las mugeres es dado; y a un tal rey como vos, con la espada en la mano. Yo os ayudaré, señor,

60 con treinta mil de cavallo; yo seré capitán d'ellos y los iré arreglando. Por las tierras donde fuere iré hiriendo y matando:

65 la villa que se me diere, harela yo derribar; la que tomare por armas, essa sembraré de sal, mataré las criaturas

70 y cuantos en ella están. Y d'esta manera iremos hasta en Troya llegar.

-Buen consejo es esse, hermano, yo assí lo quiero tomar-.

75 Ya se sale el buen rey por la ciudad a passear. Con trompetas y añafiles comiençan de pregonar: quien quisiere ganar sueldo,

80 de grado se le darán. Tanta viene de la gente que era cosa de espantar. Arman naos y galeras, comiénçanse de embarcar.

85 Agamenón los regía, todos van a su mandar. Por las tierras donde ivan van haziendo mucho mal. 
Andando noches y días,

90 a Troya van a llegar.

Los troyanos que tal saben

las puertas mandan cerrar.

Agamenón, que esto vido, mandó apercebir su real;

95 pone en orden su gente como avía de estar.

Los troyanos eran muchos, bien reparan su ciudad.

Otro día de mañana

100 la comiençan de escalar; derriban el primer paño, de dentro quieren entrar, si no fuera por don Héctor que allí se fue a hallar;

105 con él estava Troílos y el esforçado Picar.

París esfuerça su gente, que empieçan de desmayar; las vozes eran tan grandes

110 que al cielo quieren llegar. Matan tantos de los griegos que no los saben contar, más venían de otra parte que no ay cuenta ni par.

115 Entrado se an por Troya, ya la empieçan de robar. Prenden al rey y a la reina y al esforçado Picar; matan Troílos y a Héctor,

120 sin ninguna piedad, $\mathrm{y}$ al gran duque de Troya ponen en captividad.

Y sacan la reina Elena y pónenla en libertad;

125 todos le besan las manos como a reina natural. Preso llevan a París con mucha reguridad. Tres pascuas que ay en el año

130 lo mandan justiciar: sácanle ambos los ojos, los ojos de la su faz; 


\section{córtanle el pie del estribo, \\ la mano del gavilán; \\ 135 treinta quintales de hierro \\ a sus pies mandan echar, \\ y el agua hasta la cinta \\ porque pierda el cavalgar.}

Aparato de variantes: 2 vuestro $c$ ] tu $c D E$ tu alto $A B C \mid 4$ vengades $A D E]$ vengays $B C \mid 7$ aueys $B C]$ haueys $A$ vays $D E \mid 11$ nauio muy rico $B C D]$ muy rico nauio $A$ nauio al puerto $E \mid 14$ castellano $B C$ ] Castellano $D E$ de françia $A \mid 17$ aquesse $B C D E$ ] esse $A \mid 18$ mirallo $B C E]$ mirarlo $A D \mid 24$ venis $B C D]$ veuis $A$ ven s $E \mid 25$ vayades $A D]$ vades $B C E \mid 30$ ha $E]$ auia $A B C D \mid 32$ ovieron $C]$ ouieron $A B$ huuieron $D E \mid 33$ todas $B C$ ] todos $A D E \mid 34$ oyreys $D E]$ oyres $B C$ y oyres $A \mid 35$ tiendan $B C D]$ tiendas $A$ y $E \mid 36$ ha $D E]$ han $C$ an $A B \mid 38$ vn dia $A B C E]$ lunes $D \mid$ y $A D E]$ om. $B D \mid 41$ de $A B C]$ se $D E \mid 47$ traydor $D E]$ traydor de $A B C$ | 49 las $D E$ ] om. $A B C$ | palabras $A D E$ ] palabricas $B C \mid 50$ ha $A D E]$ han $C$ an $B$ | engañado $A B D E$ ] gañado $C \mid 51$ tam bien $A$ ] tambien $B C$ quan bien $D E \mid$ consolaua $A D E$ ] aconsolaua $B C \mid 55$ quel $B C]$ que $A D E \mid 57$ y $A B C E]$ om. $D \mid 58$ la $A B C]$ el $D E \mid 59$ yo os $D E]$ yos $C$ y os $A B \mid 61$ sere $A B D E]$ seray $C \mid 62$ arreglando $A B C$ ] ordenando $D E \mid 66$ derribar $A B D E]$ derribare $C \mid 67$ la $E$ ] y la $A B C D$ | 68 sal $A D E]$ sale $B$ salle $C \mid 69$ criaturas $A D E]$ creaturas $B C \mid 70$ quantos $A D E]$ quantas $B C \mid$ ella $D$ ] ellas $A B C E \mid 72$ llegar $A B C]$ allegar $D E \mid 73$ esse $A D E$ ] esto $B C \mid 74$ yo $A B C]$ y $D E \mid 76$ ciudad $A B D E]$ ciutat $C \mid$ a $A B C D]$ om. $E \mid 78$ de $A B C]$ a $D E \mid$ le $B C]$ lo $D E$ la $A \mid 85$ regia $B C]$ guia $A$ guiaua $D E \mid 91$ tal $A B C E]$ lo $D$ | 94-95 pone en orden / su $A D E]$ om. $B C \mid 96$ auia $A D E]$ auian $B C \mid 104$ fue $D E]$ fuera $A B$ fuere $C \mid 105$ Troylos $A B C$ ] Troylo $D E \mid 106$ Picar $A D E$ ] picar $B$ pican $C \mid 107$ esfuerça $B C D E$ ] sforça $A \mid 108$ empieçan $A E]$ empieça $B C$ empiençan $D$ | 110 quieren $B C D E]$ querien $A \mid 112$ los $D E]$ lo $A B C \mid$ saben $B C D E$ sabien $A$ | 113 venian $D E$ ] recrecian $A B C \mid 114$ ay $A B D E]$ ya $C$ | cuenta $A B C$ ] cuento $D E$ | 115 Troya $A D$ ] troya $B C$ la tierra $E \mid 118$ Picar $A C D E$ ] pican $D E \mid 119$ Troylos $A$ ] troylos $B$ Troylas $C$ a Troylo $D E \mid 123$ la $B C$ ] a la $A D E \mid 124$ y $A B C]$ om. $D E$ | en $A B C]$ en su $D E \mid 126$ a $B C D]$ om. $A E \mid$ natural $A B D E]$ naturale $C \mid 128$ reguridad $A B C$ ] riguridad $D E \mid 130$ lo mandan $A B C$ ] le sacan a $D E \mid 133$ cortanle $B C$ ] cortan le $D E$ cortenle $A \mid 135$ hierro $A D E$ ] fierro $B C \mid 136$ caualgar $A B D E]$ caualgare $C$.

\section{LA COMPOSICIÓN DEL ROMANCE DE LA REINA ELENA}

Desde un punto de vista narrativo, el romance de la reina Elena está compuesto por cuatro secuencias bien diferenciadas: la primera, el diálogo entre Paris y 
Elena seguido por el rapto de la bellísima reina (vv. 1-36); la segunda, el diálogo entre Menelao y Agamenón (vv. 37-74); la tercera, el relato de la conquista de Troya (vv. 75-126); la cuarta, el castigo de Paris (vv. 127-138). Menéndez Pidal pensaba que «los primeros 74 octosílabos de este romance son tradicionales y los 64 últimos son juglarescos» (1968: 353, n. 37). Esta observación no deja de plantear ciertas dificultades: mientras que la secuencia final con el castigo de Paris incorpora elementos de romances tardocarolingios o pseudocarolingios como los de Guarinos («Mal ovistes, los franceses») y Gaiferos («Estávase la condessa»), según ya había observado Menéndez Pelayo (1903: 482), la primera mitad (vv. 1-74) se ajusta en líneas generales a la leyenda troyana y por tanto cabe suponerle una base relativamente erudita. El cambio de asonancia después del v. 64 aparece en un lugar típico y no implica solución de continuidad: se produce en medio de un discurso directo, cuando el personaje comienza a elaborar con detalle una idea que acaba de anunciar - como señala en su edición Di Stefano (2010: 204), de forma similar a como ocurre en el romance que empieza «Rey don Sancho, rey don Sancho, / cuando en Castilla reinó / corrió a Castilla la Vieja...»—. Ya Catalán expuso sus reservas hacia la hipótesis de una parte inicial tradicional a la que se había añadido una continuación y prefirió no excluir «la posibilidad de que el romance ofreciese desde un principio este contraste entre una primera parte dialogada, en un estilo reminiscente del adquirido por los "romances viejos", y una continuación puramente narrativa» (1970: 104). En realidad, todo apunta a un autor que compuso un romance combinando con bastante libertad motivos de la leyenda troyana con otros ya presentes en el romancero viejo. Su tratamiento, por otra parte, no causa una impresión de gran antigüedad: más que la ausencia de la estratagema del caballo, un elemento incómodo para los cronistas alfonsíes de la General estoria y quizá no muy afín a la mentalidad caballeresca, llama la atención en el romance la rapidez con que se produce la conquista de Troya, que seguramente habría resultado extraña a un público anterior a que se extendiera el uso de la pólvora y la artillería en los asedios a fortalezas.

El estilo tradicional del romance de la reina Elena es un asunto que debería ser muy matizado, incluso en la primera mitad. La introducción del narrador en la escena con Menelao y Agamenón resulta particularmente interesante. La referencia al lunes como día funesto y aciago de los vv. 37-38 está en consonancia con una concepción muy extendida en el romancero y hasta cierto punto popular (Armistead y Silverman 1977: 177-179 n. 6; González 2000: 136-138). Sin embargo, el apóstrofe del narrador a los «cavalleros» en el v. 37 es ya poco común. Un ejemplo aún más llamativo en el que esta composición se desvía del estilo tradicional se da un poco más abajo, en el v. 43, cuando en lugar de la fórmula «de los sus ojos llorando» aparece el octosílabo «sus ojos tornados fuentes». Este aparece también en la glosa del romance de Tristán escrita por Alonso de Salaya 
que precede al de la reina Elena en los tres pliegos más recientes que lo contienen, pero es raro en el romancero. La fórmula tradicional es «de los sus ojos llorando», tal como puede observarse en numerosos romances, como el de la pérdida de España que comienza «Las huestes de don Rodrigo», el de Bernardo del Carpio «En gran pesar y tristeza», el de los infantes de Lara «Ya se salen de Castilla», el del Cid «Después que Vellido Dolfos», el de rey don Pedro «Entre la gente se suena», el del conde Dirlos «Estávase el conde Dirlos», el del marqués de Mantua «De Mantua salió el marqués», el de Reinaldos «Ya que estava don Reinaldos» o el del conde Claros «Media noche era por filo», por limitarse a ejemplos localizables en la Primavera (n. ${ }^{\text {os }} 5,11,25,32,67 \mathrm{a}, 164,165,189$ y 190 , respectivamente), a lo que cabe añadir que también se encuentra en los de tema clásico, como el de Tarquino y Lucrecia «Aquel rey de los romanos» (p. ej. en Di Stefano 1993: n. ${ }^{\circ}$ 57).

Trazar la historia de una imagen puede ser un asunto muy resbaladizo. El origen último de «ojos tornados fuentes» es con seguridad Jeremías 9.1 (8.23 en la Biblia hebrea), cuyo principio en la Vulgata leía «quis dabit capiti meo aquam et oculis meis fontem lacrimarum» y sería vertido por Casiodoro de la Reina en la Biblia del Oso de 1569 con «Oh, si mi cabeza se tornase aguas y mis ojos fuentes de lágrimas». Naturalmente, este versículo había sido traducido en las Biblias romanceadas medievales. Sin embargo, no entró a formar parte de la literatura originalmente compuesta en lengua castellana sino en fecha tardía. La expresión inicialmente aparece en la poesía devota en dos obras de difusión extraordinaria: La Passión trobada de Diego de San Pedro (m. ca. 1502?) se refiere al Redentor «con ojos tornados fuentes» (v. 38g, ed. Severin y Whinnom 1979: 124), mientras que en las Coplas «De vita Christi» de fray Íñigo de Mendoza (ca. $1424-c a$. 1508) uno de los Reyes Magos, previendo la muerte de Jesús, exclama «tornad los ojos en fuentes» (v. 238d, ed. Rodríguez-Puértolas 1968: 83). La imagen no se halla en los Evangelios y es probable que no fuera tomada directamente de la Biblia, sino de la literatura devota escrita en latín en otros países de Europa. En cualquier caso, los dos testimonios más antiguos de ambos poemas aparecen en un mismo códice, el Cancionero de Oñate-Castañeda, de hacia 1480-1485 (Harvard, Houghton Library, Sig. fMS Span 97; los versos citados en ff. 352v y 333v, respectivamente). Ambas obras debieron de ser compuestas en la década de 1470, aunque solo la de fray Íñigo de Mendoza se pueda datar con precisión gracias a sus referencias al contexto político. La primera versión de las Coplas «De vita Christi» hubo de ser escrita en el verano de 1474, en todo caso antes de la muerte de Juan Pacheco, marqués de Villena, el 4 de octubre (se alude a él como vivo), pero algún tiempo después del concilio de Aranda en diciembre del año anterior, ocasión en que aún se había mostrado partidario de Isabel el arzobispo de Toledo Alfonso Carrillo de Acuña (duramente atacado en el poema y que, dicho sea de paso, décadas atrás había bautizado con nombre troyano a su hijo natural, el conde 
Troilos Carrillo, ejemplo quizá raro pero no carente de interés) $)^{6}$. Los dos poemas estuvieron entre los grandes éxitos de la imprenta temprana: las Coplas «De vita Christi» desde que fueron impresas por primera vez en Zamora en 1482 por Antonio de Centenera o acaso algo antes por Pablo Hurus y Juan Blanco en Zaragoza (ambos establecimientos volverían sobre ellas antes de acabar el siglo) y La Passión trobada al menos desde la edición estampada en Zaragoza por Pablo Hurus en 1492, hoy perdida, pero de la cual se ha conservado una copia manuscrita y una nueva impresión del mismo taller de 1495.

La propagación de la imagen a otros géneros literarios fue rápida y amplia, por lo que aquí me limitaré a unos pocos ejemplos tempranos. Primero entró en la lírica amorosa, fuertemente teñida de alusiones religiosas, de poetas contemporáneos pero seguramente algo más jóvenes. Dos de ellos fueron Juan Álvarez Gato (ca. 1435-ca. 1512) — «tornava huentes mis ojos» en el poema que comienza «Yo's uve amor y temor» (v. 64, ed. Artiles 1928: 47, n. ${ }^{\circ}$ 39) — y Garci Sánchez de Badajoz (m. ca. 1526?) — «mis ojos tornados fuentes» en la composición que empieza «A la hora en que mi fe» (v. 12, ed. Castillo 1980: 297 [n. $\left.{ }^{\circ} 112\right]$ )—. De ahí se difundiría a la poesía bucólica portuguesa, y algún que otro escritor en castellano aficionado a ella, tras ser introducida por Bernardim Ribeiro (m. ca. 1536) en su Égloga V con «seus olhos tornados fontes» (v. 9, ed. Marques Braga 1939: 114). La imagen también se expandió fuera de la lírica y aparece en los géneros en prosa, entre los cuales quizá conviene destacar aquí la narrativa caballeresca: se puede encontrar la fórmula «sus ojos tornados fuentes» en el Arderique impreso en Valencia por Juan Viñao en 1517 (ed. Carpenter 1999: 53) o la Historia del emperador Carlo Magno y los doze pares de Francia estampada en Sevilla por Jacobo Cromberger en 1521 (ed. Baranda 1995: 611). En el transcurso del siglo XVI la imagen se acabaría convirtiendo en un manido cliché, sin acabar de perder su asociación con la poesía religiosa. Un ejemplo claro al respecto es la utilización de «sus ojos hechos fuentes» en el soneto burlesco «A un devoto» atribuido a Diego Hurtado de Mendoza (v. 8, ed. Díez Fernández 1989: 391 [n. $\left.{ }^{\circ} 218\right]$ ).

A la hora de identificar el tratamiento de la materia de Troya que inspiró al autor del romance de la reina Elena, hay que tener en cuenta que este obró con extrema libertad y que se limitó a seleccionar algunos motivos para su composición. Hay algunas reminiscencias verbales que pueden considerarse indicios, aun sin alcanzar el carácter de pruebas contundentes. Según se ha avanzado, tan solo dos secuencias del romance, el diálogo entre Paris y Elena seguido del rapto y el diálogo entre Menelao y Agamenón, guardan correspondencia con las versiones

\footnotetext{
6 Aunque no coincidan exactamente con la datación de las Coplas «De vita Christi» aquí propuesta, llaman la atención sobre estos indicios y otros similares Rodríguez-Puértolas (1968: 101-117) y Severin (2014: 34-41).
} 
existentes de la leyenda troyana. En cuanto al primero, hay que tener en cuenta que no hay un equivalente claro en los tratamientos medievales. En estos no se da una conversación entre Paris y Elena antes del robo y el romance se inspira más bien en las palabras con que él la consuela después. Tan solo hay tres obras que mencionen en este pasaje el «estado» (v. 2) de la mujer raptada. Todas ellas dependen de la ya mencionada Historia destructionis Troiae de Guido delle Colonne, que sin embargo no contiene un equivalente literal de la palabra en este lugar. La primera, las Sumas de historia troyana, de mediados del siglo XIV, se atribuye a Leomarte, citado en el texto un par de veces como autor pero las más como autoridad y que probablemente sea un erudito ficticio; se trata de la obra hispánica más temprana que emplea como fuente a Guido, combinado con otros materiales, y conoció considerable difusión e influencia a pesar de conservarse hoy solo dos manuscritos (Madrid, BNE, mss. 9256 y 6419). La segunda es la Corónica troyana, una traducción castellana anónima y fragmentaria de Guido transmitida en un códice misceláneo de hacia 1400 (San Lorenzo de El Escorial, Real Biblioteca del Monasterio, ms. L.II.16). La tercera es la Crónica troyana impresa por Juan de Burgos en 1490, a cuyo éxito editorial ya se ha aludido; se trata básicamente una combinación de las Sumas y de una traducción castellana de Guido que, hasta donde se puede comprobar, se corresponde en esencia con el fragmento escurialense recién mencionado. Este es el pasaje aludido, donde se puede observar también la relación entre las dos últimas obras:

e el vuestro estado sera reformado en muy mucho mejor con muy mayor largueza de onrra (Sumas, ed. Rey 1932: 168).

Verdaderamente cree, mj mucho amada señora, que muchas rriquezas e deleytes averas en las partes de aca e estado exçelente (Corónica troyana, ed. Pelletier Norris 1970: 119).

Verdaderamente cree, mi amada señora, que muchas más riquezas $\tau$ deleytes abrás en las partes de acá $\tau$ en mucho más onor bivirás $\tau$ estado excelente (Crónica troyana de 1490, ed. Sanz 2015: 176).

En cuanto a la segunda escena, en la cual Agamenón visita a su hermano Menelao para consolarlo y darle consejo, la expresión clave es «con la espada» (v. 58). El mismo Guido utiliza la palabra ĒNSIs, «espada», en este pasaje: «Ense igitur petenda est ulcio, non murmure querelarum» (ed. Griffin 1936: 81) — «La venganza hay que buscarla con la espada, no con murmullos de quejas» (trad. Marcos Casquero 1996: 160). A causa de ello, la alusión aparece en la mayoría de las versiones hispánicas de la Historia destructionis Troiae: «ab l'espasa» en la traducción catalana realizada entre 1367 y 1374, las Històries troianes de Jaume 
Conesa, protonotario en la cancillería real de Pedro el Ceremonioso (ed. Perujo 2015: 132); «con la spada» en la Crónica troyana aragonesa, centrada en los discursos y arengas y atribuida con motivos de peso al scriptorium de Juan Fernández de Heredia, gran maestre de la Orden de San Juan de Jerusalén, hacia 13851396 (ed. Sanz 2012: 68); «con la espada» en el Libro de la historia troyana, la única traducción castellana de Guido conservada completa, realizada por Pedro de Chinchilla en 1443 por encargo de don Alonso de Pimentel, conde de Benavente (ed. Peláez 1999: 191). Sin embargo, si nos limitamos a los tres testimonios que mencionaban el «estado», tan solo dos de ellos citan aquí tal arma. Las Sumas atribuidas a Leomarte elaboran el discurso de Agamenón de modo que omite cualquier referencia a los sollozos o la espada; así pues, estos versos del romance vienen a coincidir con el pasaje tal como aparece en el fragmento escurialense de la Corónica troyana o en la Crónica troyana impresa:

ca por muchos lloros e lágrimas njn sospiros no se aquista honor njn vengança. Por la espada, pues, es de aquistar vengança (Corónica troyana, ed. Norris 1970: 122).

que por muchos lloros $\tau$ lágrimas ni sospiros no se adquiere onor ni vengança. Por la espada, pues, es de aquirir vengança (Crónica troyana de 1490, ed. Sanz 2015: 181).

Se trata, pues, de reminiscencias que pueden considerarse indicios de que el autor del romance de la reina Elena se inspiró en una de estas dos versiones de la leyenda troyana. Es difícil decidir en cuál de ambas, pues la segunda utiliza como fuente la primera y la sigue a menudo literalmente. Resulta necesario, por tanto, examinarlas con detalle, en particular el oscuro fragmento escurialense, pues a primera vista parece un texto de escasa circulación que quizá podría ser descartado.

Según se ha indicado, se trata de un texto que aparece en un códice misceláneo de hacia 1400 conservado en El Escorial, el ms. L.II.16, procedente de la biblioteca del conde-duque de Olivares. Su contenido es como sigue: el principio (ff. 1r-74v) lo constituye la citada Corónica troyana, una traducción castellana anónima de la parte inicial de la historia de Guido; prosigue una segunda parte (ff. 74v-157r) con la versión de Alfonso XI del Roman de Troie; después esta se interrumpe para dar paso a la Historia troyana polimétrica (ff. 157r-180r), en prosa y verso; para acabar, retoma la versión de Alfonso XI del Roman de Troie (ff. 180r-353v). La traducción de la historia de Guido, que abarca los trece primeros libros y parte del decimocuarto de los treinta y cinco de que consta el original latino, es relativamente fiel, pero el prólogo está muy desfigurado, como ya advirtieron Rey y Solalinde (1942: 39). El motivo de ello es seguramente que encajaba mal con el contenido que iba a tener el códice, donde la historia de Troya se 
cuenta a partir de diversas obras. Ello hace también suponer que lo más probable es que esos capítulos traducidos de Guido fueran sacados de una versión castellana completa. Esta no pudo ser otra que la debida al canciller Pero López de Ayala (1332-1407), la primera que se hizo en castellano según antiguos testimonios y que hoy se suele dar por perdida. Existen dos noticias acerca de ella. Una es la que a mediados del siglo xv incluyó en sus Generaciones y semblanzas Fernán Pérez de Guzmán, sobrino del canciller:

Por causa d'él son conoçidos algunos libros que antes non lo eran, ansí como el Tito Libio, que es la más noble estoria romana, los Casos de los prínçipes, los Morales de Sant Grigorio, el Esidro de summo bono, el Boeçio, la Estoria de Troya (ed. Barrio 1998: 96).

El testimonio de Pérez de Guzmán es de gran interés, por ser un personaje excelentemente informado y estar muy concernido en este punto: en las Generaciones y semblanzas declara tomar como modelo precisamente a «Guido de Colupna, aquel que trasladó la Estoria Troyana de griego en latín» (ed. Barrio 1998: 67). Coincide además al respecto con un documento anterior sobre los Ayala que informa de lo siguiente sobre el canciller:

E fue ome de gran saber $\tau$ por avisar $\tau$ ennobleçer la gent $\tau$ la Nacion de Castilla fizo Romançes de latyn enl lenguaje castellano algunas coronicas et estorias que nunca antes dél fueron vistas nin conocidas en castilla entre las quales fueron la vna la estoria de Titulibio que fabla muy conplidamente los fechos de los Romanos, $\tau$ otra Estoria que es dicha Los acaecimientos de los principes $\tau$ la Estoria de troya $\tau$ el Boeçio de Consolación $\tau$ los Morales de Sant Gregorio (Zarco 1926: 156; también en Lozoya 1972: 176 según copia al parecer posterior).

Esta traducción castellana debida a la iniciativa del canciller Ayala disfrutó, pues, de gran prestigio y conoció considerable difusión, a pesar de que lo único que parece habernos llegado de ella sea el fragmento escurialense. Hay menciones en inventarios, aunque no se hayan identificado correctamente. Así, entre los bienes heredados a mediados del siglo Xvi por Isabel de Santisteban, nieta del comendador Cristóbal de Santisteban, aparece la siguiente entrada: «La Corónica troyana de mano, real y medio». Cátedra y Rodríguez Velasco (1990: 83) sugieren muy tentativamente que pudiera tratarse de la traducción de Pedro de Chinchilla, pero ha de referirse a un manuscrito con la versión de la que hablamos. Las palabras que encabezan los testimonios conservados de cada una de ellas constituyen un buen indicio: «Comjença la coronica troyana» en el caso del fragmento escurialense (ed. Norris 1970: 51), frente a «Aquí comiença el libro de la istoria troyana segund Guido de Colupna copilló, la cual trasladó de latín al nuestro 
romance Pedro de Chinchilla» (ed. Peláez 1998: 115). A ello hay que sumar que esta última no ha dejado huella alguna que permita afirmar que tuviera circulación más allá de la biblioteca de los condes de Benavente. Por último, hay que mencionar que una copia completa de la Corónica troyana de López de Ayala puede haberse conservado al menos hasta tiempos relativamente recientes. Amador de los Ríos (1863: 550) nos dice que de ella «poseyó también el docto marqués de Santillana un precioso códice, señalado hoy en la librería de Osuna, P. II, lit. M., n. ${ }^{\circ} 23 »$. Este, sin embargo, no aparece en el catálogo de manuscritos, cuatro de ellos de historiografía troyana, que de la citada biblioteca confeccionó algunos años después Rocamora (1882: 25-27). Cuando Schiff (1905: 265-268) estudió los libros del marqués de Santillana, por cierto también sobrino del canciller Ayala, consideró probable que se tratara más bien de la traducción de Pedro de Chinchilla. Se trata, no obstante, de una hipótesis insatisfactoria, pues Amador de los Ríos es muy claro y tampoco puede referirse a la copia conservada procedente de la biblioteca de los condes de Benavente (comp. Pedro de Chinchilla, ed. Peláez 1999: 93-100).

La Crónica Troyana impresa no plantea tantos problemas, pero la personalidad de su redactor sigue siendo una incógnita. Sharrer (1988) argumentó que el refundidor fue el mismo impresor Juan de Burgos. En cambio, Cátedra y Rodríguez Velasco (2000: 84-94) aventuraron la hipótesis de que pudo ser el ya mencionado comendador Cristóbal de Santisteban, regidor de Valladolid. Este realizó una labor similar al publicar por primera vez las Generaciones y semblanzas de Pérez de Guzmán como tercera parte del Mar de istorias que imprimió Diego de Gumiel en Valladolid en 1512. Sanz, en su edición de la Crónica troyana (2015: 24-26), se muestra a favor de esta hipótesis; se puede añadir que esta concuerda con los indicios de que el comendador Santisteban tenía en su biblioteca al menos una de las dos obras utilizadas para su redacción, la traducción de Guido aquí atribuida a López de Ayala. Por el contrario, hay que descartar por completo, como hacen Sharrer y Sanz, cualquier relevancia en este estado inicial de composición de la figura del humanista y religioso hispalense Pedro Núñez Delgado, docente en el Estudio de San Miguel, que un par de décadas después revisaría el texto de la Crónica troyana para una nueva edición (Sevilla, Juan Varela, 1509) con tanto éxito que su trabajo sería adoptado por los impresores posteriores.

Así pues, no se aprecia ningún elemento que permita determinar claramente si el autor del romance de la reina Elena se inspiró en la Corónica troyana probablemente debida a López de Ayala o en la Crónica troyana impresa por primera vez por Juan de Burgos en 1490. No cabe duda de que la composición del poema se halla más próxima cronológicamente a la de esta que a la de aquella, pues su empleo de imaginería divulgada por la poesía devota implica que ha de ser posterior a 1475. Aun sin pruebas definitivas, me inclino a pensar que la fuente de 
inspiración fue la Crónica troyana impresa. Ello implica que la datación del romance queda muy delimitada: el terminus post quem sería el 12 de marzo de 1490, la fecha en que el establecimiento de Juan de Burgos sacó a la luz el libro; el terminus ante quem sería el 10 de agosto de 1492, el último plazo en la expulsión de los judíos de España, lo que daría cuenta de su amplia presencia en la diáspora sefardí. Es posible que para algunas concepciones del romancero resulte una noción extrema, pero la hipótesis de un romance troyano compuesto hacia 1491 y que rápidamente se puso de moda y alcanzó popularidad resulta en realidad altamente plausible.

\section{6. «POR UNA LINDA ESPESSURA»:}

UNA COMPARACIÓN CON OTROS ROMANCES TROYANOS

Una comparación con otros romances basados en la materia de Troya puede iluminar algo más el lugar del dedicado a la reina Elena. El panorama más reciente es Gamba (2015), quien presenta un corpus de romances troyanos en el siglo XVI y señala cinco en que parece evidente un vínculo directo o indirecto con la Corónica troyana impresa. Sus implicaciones para el problema que nos ocupa son muy relativas, pues se trata de composiciones bastante tardías, con dos que aparecen por primera vez en la Séptima parte de «Flor de varios romances nuevos» a cargo de Francisco Enríquez (Madrid, Viuda de Alonso Gómez, 1595), y las partes de la historia iliense que cuenta son posteriores al punto en que se interrumpe el fragmento escurialense de la Corónica troyana. Con todo, Gamba realiza un análisis muy detallado de «En Troya entran los griegos», un romance de extensión considerable (526 vv.) escrito por Luis Hurtado de Toledo (1523-1585), y hay al menos un indicio claro de que se basa directamente en la Crónica troyana impresa y no en la Corónica troyana más arriba atribuida al canciller Ayala. El autor se sirve de meridiones (v. 189) para referirse a los mirmidones, las tropas bajo el mando directo de Aquiles y tal forma es privativa de la Crónica troyana impresa. Surgió probablemente bajo la influencia de una falsa etimología aducida aunque rechazada en las Sumas: «E dizen algunos que fueron estos de Merida e que de ally los llamaron mermidones», palabra esta última que el otro testimonio transmite como «meridones» (ed. Rey 1932: 184; se trata de ms. 9256, f. 61v, y ms. 6419, f. 50r, respectivamente); en contraste, en el fragmento escurialense de la Corónica, el cual se interrumpe antes del episodio contado por el romance, solo se encuentra «meremjdones» (ed. Norris 1970: 159). Es, pues, una señal bastante clara de que el autor de «En Troya entran los griegos» se basó en la Crónica troyana impresa. Sin embargo, no se pueden hacer extrapolaciones con un caso como el que nos ocupa. Luis Hurtado de Toledo era un escritor que ni siquiera había nacido cuando 
comenzaron a difundirse los primeros pliegos sueltos con romances troyanos y es natural que en su época la Crónica troyana impresa, que ya conocía varias ediciones, estuviera ya consolidada como fuente de romances eruditos.

Así pues, resulta más adecuado considerar el caso de otros romances troyanos tempranos. Entre ellos, hay que destacar el dedicado al juicio de Paris que comienza «Por una linda espessura». Es un poema algo más largo (184 vv.), pero según los indicios aproximadamente contemporáneo y compuesto en un mismo ambiente. Se menciona ya en el contenido del Libro de cincuenta romances (Barcelona, Carles Amorós, $c a$. 1525) y, aunque son más escasos sus testimonios en pliegos sueltos - con uno hoy perdido pero que se hallaba entre los fondos de la Biblioteca Colombina (Rodríguez-Moñino 1997: n. 110 [+966]) y otro conservado de 1549, con asignación tipobibliográfica al taller burgalés de Juan de Junta (Rodríguez-Moñino 1997: n. ${ }^{\circ}$ 874.5; Fernández-Valladares 2005: n. ${ }^{\circ} 388$ )-, fue incorporado en el Cancionero de romances s.a. (Amberes, Martín Nucio, ca. 1547), en el Cancionero de romances de 1550 del mismo impresor, la Primera parte de la Silva de varios romances (Zaragoza, Esteban de Nájera, 1550) y otras colecciones del siglo XVI (véase la lista de Piacentini 1986: n. ${ }^{\circ} 186$ ). La tradición textual presenta el mismo tipo de dificultades y errores, como casos de hipermetría (vv. 22 y 141), faltas de concordancia (v. 48) y la omisión de un octosílabo (v. 113); algunos de ellos apuntan también a que derivan probablemente de un solo pliego suelto ya defectuoso. Desde una lógica puramente narrativa, el juicio de Paris es anterior al rapto de Elena, por lo cual aquel romance suele preceder inmediatamente a este en las antologías modernas (Di Stefano 1993: 233-237, n. ${ }^{\circ}$ 59; y 2010: 197-201, n. ${ }^{\circ}$ 63; Díaz-Mas 1994: 381-385, n. ${ }^{\circ}$ 98). Además, se han publicado dos importantes estudios sobre él que plantean preguntas similares a las aquí formuladas y no siempre coinciden en las respuestas (Greer 1981; Garvin 2007: 285-299).

«Por una linda espessura», como «Reina Elena, reina Elena», es una composición basada en un pasaje de la leyenda troyana narrado en la Historia destructionis Troiae de Guido, en concreto el episodio del juicio de Paris tal como el propio príncipe lo cuenta, como una visión en sueño, ante la asamblea de nobles de Troya (Griffin 1936: 61-63; trad. Marcos Casquero 1996: 139-141). Este relato es omitido del parlamento de Paris en las Sumas, las cuales combinan diversas fuentes y ya habían contado el juicio con anterioridad (ed. Rey 1932: 159 y 151-154, respectivamente). En cambio, tanto la Corónica troyana escurialense (ed. Norris 1970: 96-98) como la Crónica troyana impresa (ed. Sanz 2015: 160-162) siguen a Guido; no obstante, en tanto que la primera se mantiene fiel a él, la segunda, aun coincidiendo por lo general casi literalmente con ella, varía en tres detalles significativos. El primero es que, mientras que en la Corónica fragmentaria la acción se sitúa «en las partes de la Pequeña Jndia», en la Crónica impresa sucede 
«en las partes de la pequeña Bretaña». La lección de Guido «in Minori India», esto es, «en la India Menor», proviene de la del Roman de Troie de Benoît «en Inde la Menor» (v. 3861). Constans (1904: 197; 1912: 236, n. 3) la explicó como posible error de lectura por «in Ida monte» con la última palabra abreviada, pues el pasaje correspondiente en De excidio Troiae historia de Dares Frigio lee aquí «in Ida silva». Así pues, el redactor de la Crónica troyana de 1490 modificó una lección poco satisfactoria de un modo que puede resultar sorprendente al lector actual, pero que no lo es tanto si se recuerdan los lazos que se establecían entre las materias de Troya y de Bretaña. El segundo cambio es la fecha: «Vn dia viernes», el día de Venus, la triunfadora en el juicio, traduce fielmente la Corónica escurialense el «dia Veneris» de Guido; en contraste, la Crónica impresa lo cambia a «un día lunes», el día de la luna, un cambio afín a la mentalidad del autor del romance de la reina Elena, donde se concebía el lunes como día nefasto y aciago, ligado a la destrucción de Troya (vv. 37-38). La tercera alteración es que el dios que conduce a las diosas ante Paris en la Corónica fragmentaria es Mercurio, tal como ocurre en Guido, mientras que en la Crónica de 1490 es Júpiter. Esta sustitución es claramente una intervención del redactor de esta última. En las versiones de la leyenda troyana más detalladas sobre el juicio, las tres diosas acuden a Júpiter, quien hace que Mercurio las conduzca ante Paris. Sin embargo, puede llegar a omitirse uno de los dos dioses. En Guido, que cuenta el juicio desde el punto de vista de Paris, Júpiter no llega a aparecer, pues el joven príncipe no lo llega a ver. Otros tratamientos de la leyenda troyana, en cambio, simplifican el relato eliminando a Mercurio y esto es lo que ocurre en las Sumas atribuidas a Leomarte. El redactor de la Crónica de 1490, que se había servido de ellas en una exposición anterior (ed. Sanz 2015: 148-150), siguió el texto de la Corónica en el relato que Paris hace de su juicio, pero sustituyó a Mercurio por Júpiter para dar consistencia a su narración.

Hay numerosos ecos verbales que indican que el autor de «Por una linda espessura» se sirvió de la Corónica o la Crónica impresa, que suelen emplear las mismas palabras en este pasaje. El ejemplo más distintivo al respecto es el poco común cultismo filosomía, «fisonomía» (v. 66), que aparece en ambas historias (ed. Norris 1970: 98; ed. Sanz 2015: 161). Así pues, cabría esperar que alguno de los tres detalles explicados proporcionara una pista sobre el texto utilizado en la composición del romance. Sin embargo, ello no ocurre. En el caso de la localización, el poeta tira por la calle de en medio y no sitúa la trama ni en la India Menor ni en la Pequeña Bretaña, sino «en Turquía» (v. 6), un cambio basado probablemente no solo en la realidad geográfica sino también en la identificación entre Turci y Teucri, «turcos»y «teucros», muy generalizada en ese periodo. Además, omite decir el día y ningún dios masculino interviene en la acción. Con ello, de 
forma similar a como ocurre con el romance de la reina Elena, resulta imposible determinar si el autor se inspiró en la Corónica o en la Crónica impresa.

El poeta de «Por una linda espessura» también muestra una actitud muy semejante respecto a la tradición romanceril previa. Según se ha indicado, el autor de «Reina Elena, reina Elena» recurría para concluir su composición a los romances de Guarinos y Gaiferos. Por su parte, el de «Por una linda espessura» se sirve del romance del prisionero que comienza «Por el mes era de mayo», situando el juicio de Paris en dicho mes. En este punto se vuelve a desviar conscientemente de Guido y las versiones castellanas de la leyenda troyana que lo toman como fuente: tanto la Corónica escurialense como la Crónica impresa indican inequívocamente que el certamen se desarrolló «en tiempo de verano, quando el sol fazía su curso so el signo de cranco», por citar solo la última (ed. Sanz 2015: 160). Hay aquí, sin embargo, un aspecto que merece notarse, y es que Guido se desvía en este punto de Benoît. Mientras que el juez siciliano apuntaba «celebrante sole solsticium estuale, dum sol sub principio Cancri ageret cursum suum» (ed. Griffin 1936: 61; «cuando el Sol estival se hallaba en su solsticio y comenzaba su curso partiendo de Cáncer», trad. Marcos Casquero 2005: 139), el clérigo francés había escrito «es calendes de mai» (v. 3860, ed. Constans 1904: 197). Esta indicación fue respetada además por adaptaciones hispánicas del Roman de Troie, por ejemplo la versión castellana de Alfonso XI, cuyo principal testimonio es un códice terminado de copiar en 1350 en el scriptorium real (San Lorenzo de El Escorial, Real Biblioteca del Monasterio, ms. h.I.6) que aquí lee «en dia de las calendas de mayo» (ed. Parker 1977: 43). Así pues, se suscita la duda de si el autor del romance del juicio de Paris pudo conocer algún otro tratamiento además de la versión castellana de Guido que claramente fue su fuente principal.

Por último, está la cuestión planteada por la pervivencia del romance del juicio de Paris en la tradición sefardí, un problema examinado por Greer (1981: 336338). El aspecto que probablemente llama más la atención en el texto impreso en el siglo XVI es la ausencia de la manzana maravillosa, elemento de rigor en todas las versiones medievales de la leyenda troyana. Sin embargo, en la tradición sefardí vuelve a aparecer, pero de forma desplazada, como un regalo ofrecido por la tercera y última competidora al juez si sentencia que es la más bella. Esta alteración puede parecer extraña al lector actual, pero desde el punto de vista de la lógica narrativa enlaza con las versiones orales del romance de la reina Elena: si la manzana maravillosa ha sido entregada a Paris, es más natural que este lleve después el manzano de oro en su barco. Ya se ha apuntado más arriba que la difusión de este último motivo hace pensar que figuraba en el romance original sobre el rapto de Elena. Greer plantea la posibilidad de que la manzana maravillosa fuera reintroducida por la tradición oral, pero se decanta en contra. En su análisis observa que la versión sefardí reduce el contenido del romance impreso en el siglo xvI; 
no obstante, contiene otro detalle que no aparece en este y sí en Guido y la versión castellana en que se basó el poeta original, a saber, que Paris ha atado su caballo antes de echarse. Esto hace que Greer se incline a pensar que la manzana de oro era también un elemento que figuraba en la composición primigenia. Se produce, pues, una tesitura muy similar a la que planteaba el romance de la reina Elena: la posible eliminación de un motivo maravilloso en un pliego suelto que fue la base de los testimonios impresos conservados del siglo XVI.

La única limitación del estudio de Greer (1981) acaso sea que su corpus se detiene en la Corónica troyana escurialense y no llega a la Crónica troyana impresa, por aquel entonces todavía necesitada de una edición asequible. Ello hace que identifique a aquella como fuente del romance del juicio de Paris a partir de pasajes que aparecen igualmente en esta. En contraste, Garvin (2007: 299) sugiere que debió de ser impreso por primera vez en Sevilla en el taller de los Cromberger, que el 24 de septiembre de 1519 sacó a la luz una edición de la Crónica troyana y volvería a publicarla al menos otras cuatro veces más durante el siglo XvI, aduciendo que a veces estampó pliegos con romances como reclamo de sus propios libros. Se trata de un planteamiento que llega a encajar con las primeras documentaciones de «Por una linda espessura»; sin embargo, tropieza con dificultades si se intenta aplicar al caso de «Reina Elena, reina Elena», que aparece en un medio pliego de Carles Amorós con asignación tipobibliográfica hacia 1510 (aparte de soslayar la cuestión de la tradición oral sefardí, a la que habría que buscar alguna explicación alternativa).

La princeps de la Crónica troyana fue sacada a la luz por la imprenta de Juan de Burgos el 12 de marzo de 1490. Poco más de un año después, el 24 de junio de 1491, volvió a salir una edición de otro taller burgalés, el de Fadrique de Basilea, que también estampó pliegos con romances según asignaciones tipobibliográficas bastante fiables. La mayoría de los que han transmitido «Por una linda espessura» $\mathrm{y}$ «Reina Elena, reina Elena» proceden de este mismo establecimiento cuando ya había pasado a manos de sus herederos. Estas dos composiciones utilizan elementos de la Crónica troyana impresa y lo más probable es que sus autores (quizá uno solo) los conocieran por una de esas dos tempranas ediciones. El primer pliego burgalés conservado con el romance de la reina Elena, probablemente impreso hacia 1520 por Alonso de Melgar, yerno de Fadrique de Basilea, puede parecer algo tardío. Sin embargo, deriva de una rama independiente respecto al testimonio más antiguo (el medio pliego estampado en Barcelona por Carles Amorós hacia 1510) y el lugar secundario que da al poema indica que ya había dejado de ser una novedad. Todo ello concuerda con la idea de que hubo una primera moda de romances troyanos hacia 1491, durante la cual se compusieron y popularizaron tanto «Reina Elena, reina Elena» como «Por una linda espessura», necesariamente presentes en la fase temprana de la divulgación de romances en pliegos sueltos. 


\section{BIBLIOGRAFÍA}

Álvarez Gato, Juan (1928). Obras completas. Jenaro Artiles Rodríguez (ed.). Madrid: Compañía Iberoamericana de Publicaciones.

Amador de los Ríos, José (1863). Historia crítica de la literatura española. Madrid: José Fernández Cancela, vol. 4.

Arderique (Valencia, Juan de Viñao, 1517) (2000). Dorothy Molloy Carpenter (ed.). Alcalá de Henares: Centro de Estudios Cervantinos.

Armistead, Samuel G. y Joseph H. Silverman (1971). The Judeo-Spanish Ballad Chapbooks of Yacob Abraham Yoná. Berkeley, Los Ángeles / London: University of California Press.

Benoît de Sainte-Maure (1904 y 1912). Le Roman de Troie. Léopold Constans (ed.). Paris: Societé des Anciens Textes Français, vols. 1 y 6.

La Biblia del Oso, según la traducción de Casiodoro de la Reina, publicada en Basilea en el año 1569 (1987). Gonzalo Flor Serrano (ed.). Madrid: Alfaguara, vol. 3.

Biblia Sacra iuxta vulgatam versionem (2007). Robert Weber y Roger Gryson (eds.). Stuttgart: Deutsche Bibelgesellschaft.

Catalán, Diego (1970). Por campos del romancero. Estudios sobre la tradición oral moderna. Madrid: Gredos.

CÁtedra, Pedro M. (1983). Seis pliegos poéticos barceloneses desconocidos, c. 1540. Madrid: El Crotalón.

CÁtedra, Pedro M. y Jesús Rodríguez-Velasco (2000). Creación y difusión de «El Baladro del sabio Merlín» (Burgos, 1498). Salamanca: Seminario de Estudios Medievales y Renacentistas.

Chinchilla, Pedro de (1999). Libro de la Historia Troyana. María Dolores Peláez Benítez (ed.). Madrid: Editorial Complutense.

Colón, Hernando (1992). Abecedarium B y Supplementum. Edición facsímil de los manuscritos conservados en la Biblioteca Colombina de Sevilla. Madrid / Sevilla: Fundación Mapfre América / Cabildo de la Catedral de Sevilla.

La Corónica Troyana. A Medieval Spanish Translation of Guido de Colonna's «Historia Destructionis Troiae» (1970). Frank Pelletier Norris II (ed.). Chapel Hill: University of North Carolina Press.

Crónica Troyana [Juan de Burgos, 1490$]$ (2015). María Sanz Julián (ed.). Zaragoza: Institución «Fernando el Católico».

Di Stefano, Giuseppe (1988). «El Romance de don Tristán. Edición “crítica” y comentarios». En Carlos Alvar (coord.), Studia in honorem prof. M. de Riquer. Barcelona: Quaderns Crema, vol. 3, pp. 271-303.

Di Stefano, Giuseppe (2016). «Los albores de la documentación romanceril. Experiencias de un editor». Abenámar, 1, pp. 117-128. 
Documentos para la historia de la imprenta y librería en Barcelona (1474-1553) (1955). Jose M. ${ }^{a}$ Madurell Marimón y Jorge Rubió y Balaguer (eds.). Barcelona: Gremios de Editores, de Libreros y de Maestros Impresores.

Fernández de Heredia, Juan (2012). Crónica Troyana. María Sanz Julián (ed.). Zaragoza: Prensas de la Universidad.

Fernández Vega, María del Mar (2003). «Política y propaganda en los pliegos sueltos poéticos catalanes (siglo XVI)». eHumanista, 3, pp. 77-90.

Fernández-Valladares, Mercedes (2005). La imprenta en Burgos (1501-1600). Madrid: Arco.

Fernández-Valladares, Mercedes (2006). «Indicios y evidencias para la asignación tipobibliográfica de los pliegos sueltos burgaleses del siglo XVI». En Pedro Cátedra (coord.), La literatura popular impresa en España y en la América colonial: formas y temas, géneros, funciones, difusión, historia y teoría. Salamanca: Seminario de Estudios Medievales y Renacentistas, pp. 437-475.

Fernández-Valladares, Mercedes (2012). «Biblioiconografía y literatura popular impresa: la ilustración de los pliegos sueltos burgaleses (o de babuines y estampas celestinescas)». eHumanista, 21, pp. 87-131.

Gamba Corradine, Jimena (2015). «El corpus de romances troyanos (siglo XVI) y la Crónica troyana de 1490». Troianalexandrina, 15, pp. 51-98.

GARvin, Mario (2007). Scripta manent. Hacia una edición crítica del romancero impreso (siglo XVI). Madrid / Frankfurt a. M.: Iberoamericana / Vervuert.

GonZÁlez, Aurelio (2000). «Fórmulas en el romancero: elementos significativos». En Florencio Sevilla y Carlos Alvar (coords.), Actas del XIII Congreso de la Asociación Internacional de Hispanistas, Madrid 6-11 de julio de 1998. Madrid: Castalia, vol. 1, pp. 134-140.

Greer, Margaret R. (1981). «Mythological and Ballad Traditions in "Por una linda espesura"». En Luis A. Ramos-García y Néstor Lugones (coords.), Studia Hispanica in Honour of Rodolfo Cardona. Madrid: Cátedra, pp. 325-338.

Guido de Columnis (1936). Historia Destructionis Troiae. Nathaniel Edward Griffin (ed.). Cambridge, MA: Mediaeval Academy of America.

Guido delle Colonne (1996). Historia de la destrucción de Troya. Manuel A. Marcos Casquero (trad.). Madrid: Akal.

Historias caballerescas del siglo XVI (1995). Nieves Baranda (ed.). Madrid: Turner, vol. 2. Hurtado de Mendoza, Diego (1989). Poesía completa. José Ignacio Díez Fernández (ed.). Barcelona: Planeta.

LAmarCA, Montserrat (2015). La impremta a Barcelona (1501-1600). Departament de Cultura de la Generalitat de Catalunya <http://cultura.gencat.cat/web/.content/ sscc/gt/arxius_gt/La-impremta-a-BCN.pdf> [Consulta: 10/12/2016].

Leomarte (1932). Sumas de historia troyana. Agapito Rey (ed.). Madrid: S. Aguirre («Anejos de la Revista de Filología Española», 15). 
Lozoya, Juan de Contreras y López de Ayala, Marqués de (1972). Introducción a la biografía del Canciller Ayala. Bilbao: Junta de Cultura de Vizcaya.

Mendoza, fray Íñigo de (1968). Cancionero. Julio Rodríguez-Puértolas (ed.). Madrid: Espasa-Calpe.

Menéndez y Pelayo, Marcelino (1899 y 1903). Antología de poetas líricos castellanos. Madrid: Hernando y Compañía / Perlado, Páez y Compañía, vols. 8-9 y 12.

Menéndez Pidal, Ramón (1968). Romancero Hispánico (hispano-portugués, americano y sefardi). Madrid: Espasa-Calpe, vol. 1.

Norton, F. J. (1978). A Descriptive Catalogue of Printing in Spain and Portugal, 15011520. Cambridge: Cambridge University Press.

Pérez de Guzmán, Fernán (1998). Generaciones y semblanzas. José Antonio Barrio (ed.). Madrid: Cátedra.

Perujo Melgar, Joan M. (2015). Les «Històries troianes» de Jaume Conesa, traducció catalana de la «Historia destructionis Troiae» de Guido delle Colonne: estudi i edició. [Tesis doctoral]. Alicante: Universitat d'Alacant $<$ http://hdl.handle. net/10045/65127> [Consulta: 15/12/2017].

Piacentini, Giuliana (1986). Ensayo de una bibliografía analítica del romancero antiguo. Los textos (siglos XV y XVI). Pisa: Giardini, 2 vols.

Pliegos poéticos del s. XVI de la Biblioteca de Cataluña (1976). Madrid: Joyas Bibliográficas, vol. 2.

Pliegos poéticos españoles en la Universidad de Praga (1960). Ramón Menéndez Pidal (pról.). Madrid: Joyas Bibliográficas, vols. 1 y 2.

Pliegos poéticos góticos de la Biblioteca Nacional (1960). Madrid: Joyas Bibliográficas, vol. 2.

Pliegos sueltos de Praga (2011). Manuscriptorium $<\mathrm{http}$ //www.manuscriptorium.com/ apps/index.php?direct=record\&pid=AIPDIG-NKCR_9_H_231__ 1QCCLDA -cs> [Consulta: 06/12/2013].

Primavera y flor de romances, ó Colección de los mas viejos y mas populares romances castellanos (1856). Fernando José Wolf y Conrado Hofmanm (eds.). Berlin: A. Asher, vol. 2.

Rey, Agapito y Antonio García Solalinde (1942). Ensayo de una bibliografía de las leyendas troyanas en la literatura española. Bloomington: Indiana University.

Ribeiro, Bernardim (1939). Éclogas. Marques Braga (ed.). Lisboa: Oficinas de S. José.

Rocamora, José María (1882). Catálogo abreviado de los manuscritos de la biblioteca del Excmo. Señor Duque de Osuna é Infantado. Madrid: Fortanet.

Rodríguez-MoÑIno, Antonio (1997). Nuevo diccionario bibliográfico de pliegos sueltos poéticos (siglo XVI). Arthur L.-F. Askins y Víctor Infantes (rev.). Madrid: Castalia.

Rodríguez-PuÉrtolas, Julio (1968). Fray Íñigo de Mendoza y sus «Coplas de Vita Christi». Madrid: Gredos.

Romancero (1988). Michelle Débax (ed.). Madrid: Alhambra.

Romancero (1993). Giuseppe Di Stefano (ed.). Madrid: Taurus. 
Romancero (1994). Paloma Díaz Mas (ed.), Samuel G. Armistead (pról.). Barcelona: Crítica.

Romancero (2010). Giuseppe Di Stefano (ed.). Madrid: Castalia.

Romances de Tetuán (1952). Arcadio de Larrea Palacín (ed.). Madrid: Instituto de Estudios Africanos, vol. 1.

San Pedro, Diego de (1979). Obras completas. Dorothy S. Severin y Keith Whinnom (eds.). Madrid: Castalia, vol. 3.

SÁnchez de Badajoz, Garci (1980). Cancionero. Julia Castillo (ed.). Madrid: Editora Nacional.

Schiff, Mario (1905). La Bibliothèque du marquis de Santillane. Paris: Émile Bouillon.

SEVERIN, Dorothy Sherman (2014). Religious Piety and Religious Humour: Lives of Christ in Late Fifteenth-Century Castile. Cancionero Virtual: An Electronic Library of the 15th-Century Castilian Cancionero Manuscript Corpus <http:// cancionerovirtual.liv.ac.uk/book.htm> [Consulta: 16/03/2018].

Sharrer, Harvey L. (1988). «Juan de Burgos, impresor y refundidor de libros caballerescos». En María Luisa López-Vidriero y Pedro M. Cátedra (coords.), El libro antiguo español: Actas del primer Coloquio Internacional (Madrid, 18 al 20 de diciembre de 1986). Salamanca / Madrid: Universidad de Salamanca / Biblioteca Nacional de Madrid / Sociedad Española de Historia del Libro, pp. 361-369.

La Versión de Alfonso XI del «Roman de Troie» Ms. H-j-6 del Escorial (1977). Kelvin M. Parker (ed.). Normal, Illinois: Applied Literature Press.

WiLKInson, Alexander S. (2015). Iberian Books / Libros ibéricos. Iberian Book Project $<$ http://iberian.ucd.ie> [Consulta: 26/03/2018].

Zarco Cuevas, Julián (1926). Catálogo de los manuscritos castellanos de la Real Biblioteca de El Escorial. Madrid: Imprenta Helénica, vol. 2.

Recibido: 18/07/2018

Aceptado: 08/08/2018 


\section{El romance de la Reina Elena en El SIGLO XVI}

RESUMEN: El romance que comienza «Reina Elena, reina Elena» ha sido transmitido por cinco pliegos sueltos del siglo XVI. Un análisis indica que todos ellos derivan de un solo ascendiente común ya defectuoso, probablemente un pliego anterior hoy perdido. Se elabora, pues, una edición crítica del poema, seguida de un estudio. El romance usa imaginería que se extiende en la literatura peninsular en lengua vernácula a partir de su introducción en la poesía devota, en concreto en las Coplas «De vita Christi» de fray Íñigo de Mendoza, cuya primera redacción es datada en el año 1474, y La Passión trobada de Diego de San Pedro, compuesta durante esa misma década. Un estudio de las posibles fuentes para los episodios narrados apunta a que el autor se basó o bien en la Corónica troyana (un traslado al castellano de la Historia destructionis Troiae de Guido delle Colonne, conservado fragmentariamente y aquí identificado con el debido al canciller Pero López de Ayala) o la Crónica troyana impresa por primera vez en 1490 (un texto que combina las Sumas de historia troyana atribuidas a Leomarte y la Corónica troyana recién mencionada). A pesar de la ausencia de pruebas definitivas, lo más probable es que hubiera hacia 1491 una primera moda de romances troyanos inspirados en la Crónica troyana impresa. En tal momento debió de componerse «Reina Elena, reina Elena», así como el contemporáneo «Por una linda espessura», que se hicieron rápidamente populares y entraron en la tradición oral sefardí.

PALABRAS ClAVE: romances, materia de Troya, pliegos sueltos, ecdótica.

\section{THE SPANISH BALLAD OF HELEN OF TROY IN THE 16TH CENTURY}

ABSTRACT: The Spanish ballad of Helen of Troy has been transmitted in five chapbooks of the 16th century. An analysis shows that all of them derive from an already faulty common ascendant, presumably a lost chapbook. A critical edition of the poem is presented, and a study follows. This ballad uses imagery first introduced in Spanish vernacular literature by devotional poetry, namely Fray Íñigo de Mendoza's Coplas "De vita Christi", the date of which is pinpointed to 1474, and Diego de San Pedro's La Passión trobada, also composed in the 1470s. A study of the sources for this ballad shows that it is mainly based either on the Corónica troyana (a Castilian translation of Guido delle Colonne's Historia destructionis Troiae ascribed here to Pero López de Ayala's initiative, fragmentarily preserved) or on the Crónica troyana first printed in 1490 (a text combining the 14th-century Sumas de historia troyana attributed to Leomarte and the above-mentioned Corónica troyana). Despite the lack of conclusive evidence, the most likely explanation is that there was a first fashion of Trojan ballads ca. 1491 inspired by the incunabular Crónica troyana. The ballad on the Abduction of Helen, as well as the contemporary one on the Judgment of Paris, were composed at that time, becoming quickly popular and entering Sephardic oral tradition.

KEYWORDS: ballads, matter of Troy, chapbooks, textual criticism. 


\section{Edad de Oro. Revista de Filología Hispánica}

ISSN: 0212-0429 - ISSNe: 2605-3314 <https://revistas.uam.es/edadoro/index>

Edad de Oro es uno de los máximos referentes en el área de investigación en Filología Hispánica, especialmente de los siglos XVI y XVII. Goza de un amplio reconocimiento en el ámbito académico internacional. Desde 1982 publica ininterrumpidamente, con una periodicidad anual, colaboraciones científicas de los principales especialistas de diversos centros nacionales y extranjeros. Con un público compuesto esencialmente por investigadores y expertos de todo el mundo, se dirige a cualquier persona interesada en las nuevas corrientes de los estudios humanísticos de su campo.

Dirección:

María Jesús Zamora Calvo

(Univ. Autónoma de Madrid)

Subdirección:

José Antonio Llera Ruiz

(Univ. Autónoma de Madrid)

Secretaría:

Raquel Arias Careaga

(Univ. Autónoma de Madrid)

Consejo de redacción:

Cecilia López-Ridaura

(ENES. Morelia / Univ. Nacional

Autónoma de México)

José Luis Ocasar Ariza

(Univ. Autónoma de Madrid)

Rocío Pérez Gironda

(Univ. Autónoma de Madrid)

Carolina Fernández Cordero

(Iberoamericana-Vervuert)

Admisión de originales:

María Jesús Zamora Calvo

Edad de Oro

Universidad Autónoma de Madrid

Facultad de Filosofía y Letras

Departamento de Filología Española

Campus Cantoblanco

28049 Madrid (España)

Tfno. (+34) 914976886

Correo-e: mariajesus.zamora@uam.es

Distribución, suscripción y venta:

Servicio de Publicaciones de la UAM

Universidad Autónoma de Madrid

28049 Madrid (España)
Intercambio de publicaciones:

Biblioteca de Humanidades

Universidad Autónoma de Madrid

28049 Madrid (España)

Comité científico:

Carlos Alvar (Université de Gèneve)

Ignacio Arellano (Univ. de Navarra)

Alberto Blecua

(Univ. Autónoma de Barcelona)

Jean Canavaggio

(Université Paris Nanterre)

Aurora Egido (Univ. de Zaragoza)

Víctor García de la Concha (RAE)

Luciano García Lorenzo (CSIC)

Joaquín González Cuenca

(Univ. de Castilla la Mancha)

Agustín de la Granja López

(Univ. de Granada)

Begoña López Bueno (Univ. de Sevilla)

Michel Moner

(Universitè Toulouse - Jean Jaurès)

Joan Oleza (Univ. de Valencia)

Alfonso Rey

(Univ. de Santiago de Compostela)

Lina Rodríguez Cacho

(Univ. de Salamanca)

Leonardo Romero Tobar

(Univ. de Zaragoza)

Aldo Ruffinatto

(Università degli Studi di Torino)

Lía Schwartz

(City University of New York)

Han colaborado en este volumen:

Departamento de Filología Española

(UAM)

Facultad de Filosofía y Letras (UAM)

Edad de Oro se recoge en las siguientes bases de datos y directorios: DICE; HLAS; MLA International Bibliography; PIO; ISOC-CSIC; DIALNET; SUMARIS CBUC; ULRICH'S.

Se encuentra evaluada en: SCOPUS: Q2; SCImago: SJR 2017 0.11, H Index 4; ERIH Plus: category A; CIRC: categoría C; RESH: 0.162; MIAR: ICDS 2017 10.0; CARHUS Plus+: C; LATINDEX. 


\section{EDAD DE ORO}

Revista de Filología Hispánica XXXVII

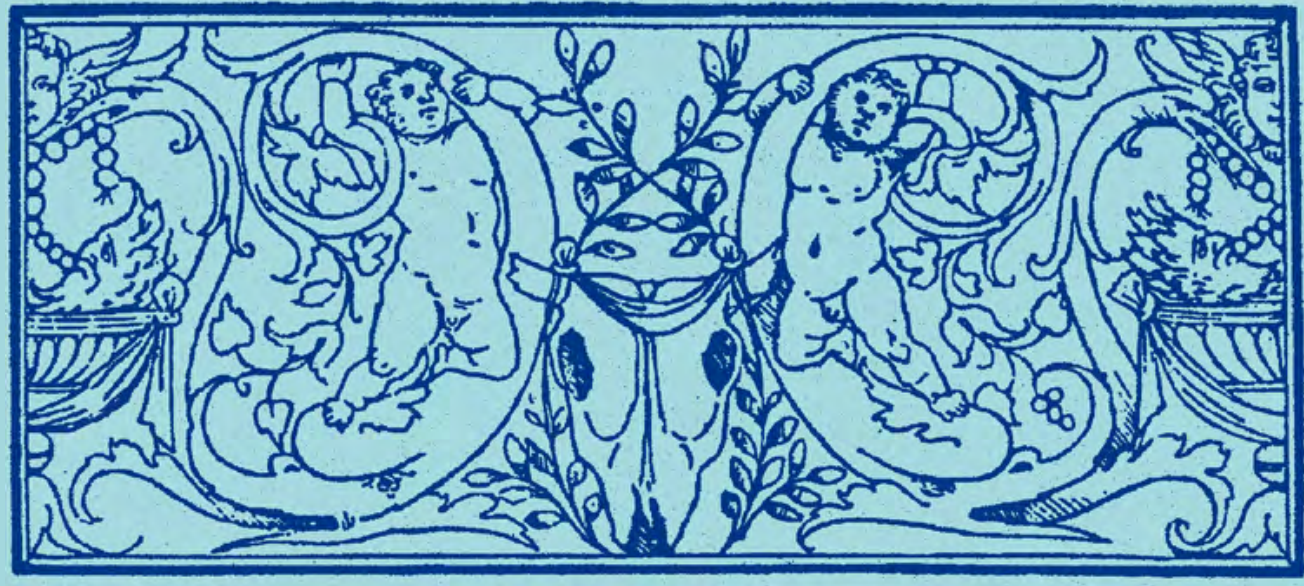

\section{DEPARTAMENTO DE FILOLOGÍA ESPAÑOLA}

EDICIONES DE LA UNIVERSIDAD AUTÓNOMA DE MADRID 